Fachbereich 5

Wirtschaftswissenschaften, Wirtschaftsinformatik und Wirtschaftsrecht

\title{
Volkswirtschaftliche Diskussionsbeiträge
}

Discussion Papers in Economics

No. $134-09$

August 2009

Thomas Eichner $\cdot$ Rüdiger Pethig

EU-type carbon emissions trade and the distributional impact of overlapping emissions taxes 


\section{Universität Siegen}

Fachbereich 5

Wirtschaftswissenschaften, Wirtschaftsinformatik und Wirtschaftsrecht

Fachgebiet Volkswirtschaftslehre

Hölderlinstraße 3

D-57068 Siegen

Germany

http://www.uni-siegen.de/fb5/vwl/

ISSN 1869-0211

Available for free from the University of Siegen website at http://www.uni-siegen.de/fb5/vwl/research/diskussionsbeitraege/

Discussion Papers in Economics of the University of Siegen are indexed in RePEc and can be downloaded free of charge from the following website:

http://ideas.repec.org/s/sie/siegen.html 


\title{
EU-type carbon emissions trade and the distributional impact of overlapping emissions taxes*
}

\author{
Thomas Eichner \\ Department of Economics, University of Bielefeld \\ Rüdiger Pethig \\ Department of Economics, University of Siegen
}

\begin{abstract}
The European Union fulfills its emissions reductions commitments by means of an emissions trading scheme covering some part of each member state's economy and by national emissions control in the rest of their economies. The member states also levy energy/emissions taxes overlapping with the trading scheme. Restricting our focus on cost-effective policies, this paper investigates the distributive consequences of increasing the overlapping emissions tax that is uniform across countries. For quasi-linear utility functions and for a class of parametric utility and production functions emissions tax increases turn out to be exactly offset by permit price reductions. As a consequence permit-exporting [permit-importing] countries lose [gain] from an increase in the emissions tax. These results are not general, however. By means of a numerical example we show that export-import reversals and welfare reversals are possible.
\end{abstract}

JEL classification: H21, H22, Q56

Key words: emissions taxes, emissions trading, international trade

${ }^{*}$ Eichner: Department of Economics, University of Bielefeld, Universitätsstr. 25, 33615 Bielefeld, Germany, phone: ++ 49 (0) 521106 4857, email: teichner@wiwi.uni-bielefeld.de; Pethig: Department of Economics, University of Siegen, Hölderlinstr. 3, 57068 Siegen, Germany, phone: ++ 49 (0) 2717403143 , email: pethig@vwl.wiwi.uni-siegen.de 


\section{Introduction}

In the Kyoto Protocol the EU committed to reduce its greenhouse gas emissions by $8 \%$ in 2012 from its baseline emissions in 1990. In order to fulfill this commitment the EU has established an emissions trading scheme (ETS) in 2005 (see EU 2003a) allowing for EU-wide trade in emissions permits. With respect to emissions control the economies of all member states are split into two sectors. The installations covered by the ETS, referred to as the ETS sector, include combustion installations, mineral oil refineries, coke ovens, installations producing and processing ferrous materials, mineral installations and industrial plants for the production of pulp and paper. In the rest of the economy, called the non-ETS sector (that mainly consists of private households and transportation), emissions control is the national governments' responsibility and is carried out through instruments other than emissions trading. Another peculiarity of EU emissions control is the existence of emissions or energy taxes in the ETS sectors overlapping with the ETS (Johnstone 2003, Sorrell and Sijm 2003). Table 1 lists exemplarily selective overlapping energy taxes in ETS-sectors. ${ }^{1}$

\begin{tabular}{|l||c|c|c|}
\hline & $\begin{array}{c}\text { Coal } \\
\text { in industry }\end{array}$ & $\begin{array}{c}\text { Heavy fuel oil for } \\
\text { combustion installations }\end{array}$ & $\begin{array}{c}\text { Light fuel oil } \\
\text { in industry }\end{array}$ \\
\hline \hline Austria & 35.9 & 5.4 & 24.2 \\
Finland & 43.0 & - & 14.0 \\
France & - & - & 11.7 \\
Germany & - & 10.1 & 13.0 \\
Ireland & - & 7.0 & 8.9 \\
Poland & - & 6.4 & 12.5 \\
Spain & - & - & 16.6 \\
Sweden & - & - & 12.8 \\
\hline
\end{tabular}

Table 1: Percentage of energy taxes ${ }^{2}$ in prices in the second quarter 2007 (International Energy Agency 2007)

We aim at modeling a hybrid EU-type policy in a stylized way. Under the simplifying assumption that in their non-ETS sectors national governments control emissions through a sectoral emissions tax, box 2 in Table 2 shows the mix of complementary and overlapping policy instruments that will be focused here. Box 1 in Table 2 represents the limiting case

\footnotetext{
${ }^{1}$ The 'Energy Tax Directive' (EU 2003b) sets minimum tax levels on fossil fuel starting in 2004. It allows for many exemptions and tax reductions, e.g. for energy-intensive business. Art. 14 stipulates that Member States shall exempt from taxation energy products used to produce electricity but on the other hand it allows Member States to subject these energy products to taxation without having to respect the minimum levels of taxation laid down in the Directive. The effect of the Directive is small because most countries have higher rates than the minimums.

${ }^{2}$ VAT is not included in prices and taxes shown for industry and electricity generation because it is refunded.
} 
in which no tax is levied in the ETS sector while box 3 can be interpreted as the state in which the rate of the tax in the ETS sector is so high as to 'dry up' the permit market.

\begin{tabular}{|l||c|c|c|}
\cline { 2 - 4 } \multicolumn{1}{c||}{} & \multicolumn{3}{c|}{ Emissions control in the ETS sector via } \\
\cline { 2 - 4 } & ETS & ETS and sectoral tax & Sectoral tax \\
\hline \hline \multirow{2}{*}{$\begin{array}{l}\text { Emissions control in the } \\
\text { non-ETS sector via sectoral tax }\end{array}$} & 1 & 2 & 3 \\
\hline
\end{tabular}

Table 2: EU-type emissions control in a two-sector economy

To capture such policies in a multi-country model we translate the EU commitment of emissions reductions into an upper bound, say $\bar{c}$, for total emissions in the group of countries. The EU burden sharing agreement (EU 1999) is then interpreted as a political decision to split the overall emissions cap $\bar{c}$ into national caps, $c_{i}$, one for each member state $i=1, \ldots, n$, satisfying $\sum_{j} c_{j}=\bar{c}$. Throughout the rest of this paper we will take the partition $\left(c_{1}, \ldots, c_{n}\right)$ of the overall cap $\bar{c}$ as given. As noted above, the EU ETS covers only part of each member state's economy. Therefore, the national cap $c_{i}$ needs to be further split into a cap for the ETS and the non-ETS sector. The cap for the non-ETS sector is then implemented by a sectoral emissions tax whereas the cap of the ETS sector defines the country's budget of emissions permits to be issued by the national government and allocated to the installations in its ETS sector.

Obviously, that hybrid policy is susceptible to many pitfalls of cost ineffectiveness, in particular when overlapping taxes in the ETS sectors are included in the policy mix. To the best of our knowledge, there are only two papers studying international emissions trading with overlapping emissions taxes. Böhringer et al. (2007) use a CGE model to study the impact of overlapping regulation through a unilateral carbon tax in one of the countries (Germany). They show that the German ETS sector carries excessive costs while the other EU member states may benefit or lose from that tax. Eichner and Pethig (2008) use a general equilibrium model to assess policy (in)effectiveness when national governments have discretion in fixing both an overlapping tax and their budget of emissions permits. Eichner and Pethig (2008) establish that cost effectiveness for the group of countries is attained if and only if there is a tax in the ETS sector (possibly zero) that is uniform across countries and a tax in the non-ETS sector that is also uniform across countries at a rate equal to the sum of the permit price and the rate of the tax in the ETS sector. The important message is that as long as the emissions tax in the ETS sectors is uniform across countries it can be fixed at different levels without compromising cost effectiveness for the group of countries. 
In the present paper we will briefly reconstruct the model developed in Eichner and Pethig (2008), restate their cost-effectiveness result, and base our subsequent analysis on that model. However, we will exclusively consider cost-effective policies disregarding (empirically existing) cost ineffective policies and possible corrective actions that are addressed by Böhringer et al. (2007) or Eichner and Pethig (2008). This restriction serves to direct as clearly as possible the focus on the objective of the present paper, namely to study the distributional consequences of variations in the overlapping emissions tax.

To our knowledge, this distributional issue has not been analyzed in a two-sector general equilibrium framework which captures the EU emissions control in a stylized way. We aim to determine the welfare effects of variations in the overlapping emissions tax. More specifically, denote by $u_{i}\left(c, t_{y}\right)$ the welfare of country $i$ in the (unique) competitive equilibrium of the multi-country model which prevails when $c=\left(c_{1}, \ldots, c_{n}\right)$ is the vector of national emissions caps and when $t_{y}$ is the rate of the emissions tax in the countries' ETS sectors. ${ }^{3}$ We are interested in the sign of the derivative $\partial u_{i}\left(c, t_{y}\right) / \partial t_{y}$ whose calculation turns out to be non-trivial because it requires carrying out a full-scale comparative static analysis of the multi-country model.

Due to the model's complexity we do not succeed in fully characterizing the distributional impact of variations in $t_{y}$ (from $t_{y}=0$ to some high level of $t_{y}$ for which the permit price becomes zero). However, we do obtain clear-cut analytical answers for the special case of quasi-linear utility as well as for a class of parametric utility and production functions. In both cases we show that an increase in the tax rate $t_{y}$ is exactly offset by a reduction in the equilibrium permit price leaving all firms' production unaffected. Yet the value of imports and exports of permits is affected, and it is shown that an individual country loses wealth to the benefit of all other countries, when it exports permits, and gains wealth at the expense of all other countries, when it imports permits.

However, the perfect offset of variations in the tax rate by changes in the equilibrium permit price turns out to be a special case that is typical only in models where the market of emissions permits is isolated from all other markets. In general, market-interdependence effects, i.e. repercussions of tax variations in markets other than the permit market, render imperfect the offset between the tax rate and the permit price. We show this by means of a numerical example in which one of the countries that initially exports permits eventually starts importing permits following successive increases in the tax rate $t_{y}$. As a consequence of that export-import reversal the country switches from welfare gains to losses. Therefore, the central message of the paper can be summarized as follows: the distributional impact

\footnotetext{
${ }^{3}$ As we restrict our attention to cost-effective policies it is necessary to assume the tax rate to be uniform across countries.
} 
of variations in the emissions tax in the countries' ETS sector is significant, and since in the real world market-interdependence effects are not negligible, that impact is less clear-cut in magnitude and direction than suggested by partial equilibrium analysis.

Those less clear-cut distributional consequences are specific, indeed, to the EU-type emissions control as modeled here. To demonstrate that more clearly, we modify our standard model of two-sector economies with a joint ETS by briefly considering a model of two-sector economies with separate national ETSs and, alternatively a model of one-sector economies with a joint ETS. In both cases market-interdependence effects turn out to be absent implying that the pertaining allocation and distribution is as in our standard model with quasi-linear preferences.

The paper is organized as follows. Section 2 sets up the model and characterizes the cost-effective allocation which is then decentralized in competitive markets by appropriate emissions control. Section 3 presents the incidence of increasing the uniform overlapping emissions tax in the ETS sector. In Section 4 we analyze modified versions of our standard model and Section 5 concludes.

\section{Cost-effective EU-style carbon emissions control}

\subsection{The model}

Consider a group of $n$ countries embedded in the world economy. The economy of each country $i(i=1, \ldots, n)$ consists of two sectors $X^{i}$ and $Y^{i}$ producing two consumption goods $x_{s i}$ and $y_{s i}$ with the help of fossil fuel, $e_{x i}$ and $e_{y i}$, by means of the production functions ${ }^{4}$

$$
x_{s i}=X^{i}\left(e_{x i}\right) \quad \text { and } \quad y_{s i}=Y^{i}\left(e_{y i}\right)
$$

that are increasing and strictly concave. The representative consumer of country $i$ derives utility from consumption $x_{i}$ and $y_{i}$ of these goods according to the quasi-concave utility function

$$
u_{i}=U^{i}\left(x_{i}, y_{i}\right)
$$

that is increasing in both arguments. Good $X$ is nontradable, and hence domestic consumption is required to match domestic production

$$
x_{i}=x_{s i} .
$$

\footnotetext{
${ }^{4}$ Upper case letters denote functions and subscripts attached to them indicate partial derivatives.
} 
Good $Y$ and fossil fuel are traded on world markets at constant prices $p_{y}$ and $p_{e}$, respectively. All fuel input is assumed to be imported from the rest of the world.

Since $\mathrm{CO}_{2}$ emissions are proportional to the input of fossil fuel, we simply denote both by the same symbols. Modeling the EU's commitment in the Kyoto Protocol to reduce its greenhouse gas emissions by 8 percent from 1990 to 2012 we assume that the group of countries as a whole restricts its total emissions to some level ${ }^{5} \bar{c}>0$. To meet that target each country is assigned a national emissions cap $c_{i} \geq 0$ like in the EU burden-sharing agreement such that $\sum_{j} c_{j}=\bar{c}$. In each country the national emissions cap needs to be split up into two sectoral caps $c_{y i}$ and $c_{x i}$ satisfying

$$
c_{i}=c_{x i}+c_{y i}
$$

The sectoral caps are assumed to restrain emissions in the following way ${ }^{6}$

$$
\begin{aligned}
c_{x i} & =e_{x i} \\
\sum_{i} c_{y i} & =\sum_{i} e_{y i} .
\end{aligned}
$$

\subsection{The cost-effective allocation}

Consider now a social planner aiming to maximize the weighted sum of the utilities of all countries' representative consumers subject to (1)-(6) and subject to the group's consolidated trade balance

$$
\sum_{j}\left[p_{y}\left(y_{s j}-y_{j}\right)-p_{e}\left(e_{x j}+e_{y j}\right)\right]=0
$$

vis-à-vis the rest of the world. Solving the associated Lagrangean

$$
\begin{aligned}
\mathcal{L} & =\sum \alpha_{j} U^{j}\left(x_{j}, y_{j}\right)+\sum_{j} \lambda_{x j}\left[X^{j}\left(e_{x j}\right)-x_{j}\right]+\sum_{j} \lambda_{c j}\left(c_{j}-c_{y j}-e_{x j}\right) \\
& +\lambda_{h} \sum_{j}\left\{p_{y}\left[Y\left(e_{y j}\right)-y_{j}\right]-p_{e}\left(e_{x j}+e_{y j}\right)\right\}+\lambda_{e} \sum_{j}\left(c_{y j}-e_{y j}\right)
\end{aligned}
$$

a cost-effective allocation is characterized by the marginal conditions

$$
\begin{aligned}
\frac{U_{y}^{i}}{U_{x}^{i}} & =\frac{p_{y}}{\mu_{x i}} \quad \text { for } i=1, \ldots, n, \\
\mu_{x i} X_{e}^{i} & =p_{y} Y_{e}^{i}=p_{e}+\mu_{e} \quad \text { for } i=1, \ldots, n,
\end{aligned}
$$

\footnotetext{
${ }^{5}$ Throughout the paper we take $\bar{c}$ to be smaller than total business-as-usual emissions $\sum_{j}\left(e_{x j}+e_{y j}\right)$.

${ }^{6}$ Equation (5) is required to hold for all $i$ and is therefore more restrictive than the constraint $\sum_{j} c_{x j}=$ $\sum_{j} e_{x j}$. The rationale of the differential treatment of the sectors $X$ and $Y$ is to model in the next section the institutional setting of the EU where the ETS covers the sectors $Y$ of all member states only while each member state is obliged to implement the cap $c_{x i}$ in its sector $X$.
} 
where $\mu_{x i}:=\lambda_{x i} / \lambda_{h}$ and $\mu_{e}:=\lambda_{e} / \lambda_{h}$, and where $\lambda_{e}, \lambda_{h}$. The cost-effective allocation requires consumption efficiency (9) by equalizing the marginal rates of substitution and the price ratios across countries, and production efficiency (10) by equalizing marginal abatement costs across sectors and countries.

\subsection{Cost-effectiveness in the competitive economy}

Having characterized in Proposition 1 the cost-effective allocation as a benchmark, we now introduce into the model (1)-(7) competitive markets for good $X$ with price $p_{x i}$ in all countries $i=1, \ldots, n$ along with the following emissions control policies: There is an emissions tax on good $Y$ at rate $t_{y i}$, an emissions tax on good $X$ at rate $t_{x i}$ and the group as a whole operates an emissions trading scheme (ETS) with mandatory participation of all countries' sectors $Y$. Henceforth we will refer to sector $Y$ as the ETS sector and to sector $X$ as the non-ETS sector. To install the ETS, each country $i$ issues the amount $c_{y i}$ of marketable emissions permits and allocates them to the firms in its ETS sector. A competitive market for permits will arise with the aggregate supply being fixed at $\sum_{j} c_{y j}$ and with the aggregate demand $\sum_{j} e_{y j}$ being determined by the permit price $\pi_{e}$ as to meet the market-clearing condition (6).

In this institutional setting the profits of the aggregate sectoral firms are $^{7}$

$$
p_{x i} X^{i}\left(e_{x i}\right)-\left(t_{x i}+p_{e}\right) e_{x i} \quad \text { and } \quad p_{y} Y^{i}\left(e_{y i}\right)-\pi_{e}\left(e_{y i}-c_{y i}\right)-\left(t_{y i}+p_{e}\right) e_{y i},
$$

and the associated first-order conditions for profit maximization read

$$
p_{x i} X_{e}^{i}\left(e_{x i}\right)=t_{x i}+p_{e} \quad \text { and } \quad p_{y} Y_{e}^{i}\left(e_{y i}\right)=t_{y i}+p_{e}+\pi_{e} .
$$

The consumer of country $i$ maximizes her utility $U^{i}\left(x_{i}, y_{i}\right)$ subject to her budget constraint

$$
z_{i}=p_{x i} x_{i}+p_{y} y_{i}
$$

where $z_{i}:=g_{x i}^{*}+g_{y i}^{*}+t_{x i} e_{x i}+t_{y i} e_{y i}$ is her income consisting of the firm's maximum profits, $g_{x i}^{*}$ and $g_{y i}^{*}$, and the tax revenues, $t_{x i} e_{x i}+t_{y i} e_{y i}$, recycled to the consumer in a lumpsum fashion. The first-order conditions for utility maximization yield the demand function for $\operatorname{good} X$

$$
x_{i}=D^{i}\left(p_{x i}, z_{i}\right) .
$$

\footnotetext{
${ }^{7}$ The way profits are defined for the ETS sector implies gratis allocation of permits to that sector. Due to the high level of abstraction of the model under consideration, allocating permits via auction would leave the results unchanged.
} 
Proposition 1. (Eichner and Pethig 2008)

The equilibrium allocation of the competitive economy (1)-(6) and (11)-(13) is costeffective, if and only if

$$
t_{x i}=t_{x} \quad \text { and } \quad t_{y i}=t_{y} \quad \text { for all } \quad i=1, \ldots, n
$$

and

$$
t_{x}=\pi_{e}+t_{y}
$$

The important message of Proposition 1 is that a cost-effective allocation can be attained by means of a policy mix consisting of an ETS and of emissions taxes satisfying (14) and (15). There is a 'degree of freedom' concerning the level of the (uniform) tax rate $t_{y}$ because for the firms in the ETS sector it is the total price of energy input and emissions, $p_{e}+\pi_{e}+t_{y}$, that matters. The firms' demand for energy and emissions permits depends on that total price irrespective of what its components are.

Casual evidence of carbon emissions control in the EU suggests that none of the three equalities in (14) and (15) are satisfied. There are positive non-uniform tax rates $t_{y i}$ in various member states as shown in Table 1 . Yet the rates $t_{y i}$ tend to be low relative to the (implicit) tax rates $t_{x i}$ and the average permit price $\pi_{e}$ was also very low during the first trading phase 2005-2007 suggesting that $t_{x i}>\pi_{e}+t_{y i}$ for many EU member states during the last years.

Although Proposition 1 provides straightforward guidelines for improving the costeffectiveness of carbon emissions control in the EU, we will not elaborate on that issue but focus, instead, on the distributional impacts of the hybrid EU-style policy mix. To avoid coping with distributional consequences of cost-ineffective allocations we will restrict our attention to cost-effective policies. In other words, (14) and (15) are assumed to hold throughout the rest of the paper. It follows that for fixed national emissions caps, $c_{i}$, the tax rate $t_{y}$ (with $t_{y i}=t_{y}$ all $i$ ) is the sole autonomous policy instrument. In practice, employing a uniform tax rate $t_{y}$ presupposes an internationally coordinated tax policy or alternatively, a supranational fiscal authority fixing the tax rate $t_{y}$ and requiring all governments to set the tax rate $t_{x}$ in their non-ETS sectors as to satisfy (15). We will make use of the latter interpretation and refer to the supranational fiscal authority as the center.

Observing the cost-effective conditions (14) and (15), the center has some discretion in fixing the tax rate $t_{y}$. In fact, there is a range of tax rates $t_{y}$ supporting cost-effective competitive equilibria with the following polar cases:

\footnotetext{
${ }^{8}$ See also the stylized analysis of overlapping regulation in Böhringer et al. (2008).
} 
(i) Suppose the center fixes the tax rate at $t_{y}=0$ (box 1 in Table 2). The cost-effective emissions control then consists of a tax-and-cap policy in each country's domestic non-ETS sector and an international ETS covering the ETS sectors of all countries. Although in this case no overlapping regulation is employed both instruments are still linked through the cost-effectiveness condition $t_{x}=\pi_{e}$.

(ii) Suppose the center fixes the rate at some high level, say $\bar{t}_{y}>0$, such that in the resultant equilibrium total demand for permits equals total supply at price $\pi_{e}=0$ (box 3 in Table 2). The cost-effectiveness condition then is $t_{x}=\bar{t}_{y}$. A strange feature of this scenario is that in spite of $\pi_{e}=0$ the market for emissions permits is still in operation. This polar case will play a benchmark role in the subsequent analysis.

It follows that associated to each $t_{y} \in\left[0, \bar{t}_{y}\right]$ there is a cost-effective competitive equilibrium (box 2 in Table 2). However, we do not yet know how these equilibria differ with respect to the distribution of the countries' income and welfare. Our goal is to explore the distributive impacts of variations in $t_{y}$. These effects will be investigated by means of a comparative static analysis of our multi-country model in the next section. To ease the exposition, we will omit some of the tedious calculations referring the reader to the full-scale comparative statics in the Appendix.

\section{Incidence of the uniform emissions tax overlapping with the ETS}

\subsection{Comparative statics using general functional forms}

In this section we start from an initial competitive equilibrium for some vector $c=\left(c_{1}, \ldots, c_{n}\right)$ of national emissions caps and for some $t_{y} \in\left[0, \bar{t}_{y}\right]$. We will leave the national emissions cap unchanged but will disturb the initial equilibrium by a small (exogenous) variation in $t_{y}$ and determine the displacement effects characterizing the new cost-effective equilibrium reached after the shock. Ultimately, we are interested in the associated redistribution of national welfare as measured by changes in the utility of the countries' representative consumers which turn out to be (Appendix A $)^{9}$

$$
\frac{\mathrm{d} u_{i}}{\lambda_{i} \mathrm{~d} t_{y}}=t_{y}\left(\frac{\alpha_{i} \delta_{i}-\beta_{i} \gamma_{i}}{\gamma_{i}}\right)\left(\frac{\mathrm{d} \pi_{e}}{\mathrm{~d} t_{y}}+1\right)+\left(\frac{\alpha_{i} t_{y} D_{z}^{i}+\gamma_{i}}{\gamma_{i}}\right) \Delta e_{y i} \frac{\mathrm{d} \pi_{e}}{\mathrm{~d} t_{y}},
$$

where $\alpha_{i}:=-\frac{X_{e}^{i}}{p_{x i} X_{e e}^{i}}>0, \beta_{i}:=-\left(\frac{1}{Y_{e e}^{i}}+\frac{1}{p_{x i} X_{e e}^{i}}\right)>0, \delta_{i}:=\alpha_{i}-\beta_{i} t_{y} D_{z}^{i}, \gamma_{i}:=\alpha_{i} X_{e}^{i}-$ $D_{p}^{i}-\left(x_{i}+\alpha_{i} t_{y}\right) D_{z}^{i}$. In addition, $\lambda_{i}>0$ is the marginal welfare of income in country $i$ and

\footnotetext{
${ }^{9}$ For convenience of notation good $Y$ is chosen as numeraire $\left(p_{y} \equiv 1\right)$.
} 
$\Delta e_{y i}:=c_{i}-e_{x i}-e_{y i}$ is the amount of permits exported $\left(\Delta e_{y i}>0\right)$ or imported $\left(\Delta e_{y i}<0\right)$ by country $i$. Although it can be shown (Appendix A) that $\alpha_{i} \delta_{i}>\beta_{i} \gamma_{i}$ and that $\gamma_{i}>0$ under weak restrictions, (16) only yields limited information on the sign of $\mathrm{d} u_{i} / \mathrm{d} t_{y}$. We are able to infer from (16) that $\operatorname{sign} \frac{\mathrm{d} u_{i}}{\mathrm{~d} t_{y}}=-\operatorname{sign} \Delta e_{y i}$, if $t_{y}=0$ and $\mathrm{d} \pi_{e} / \mathrm{d} t_{y}<0$, and that

$$
\left.\left.\frac{\mathrm{d} u_{i}}{\mathrm{~d} t_{y}}<0, \quad \text { if } \quad t_{y}>0, \Delta e_{y i}>0, \frac{\mathrm{d} \pi_{e}}{\mathrm{~d} t_{y}} \in\right]-1,0\right]
$$

and if $\eta_{x z}^{i}:=x_{i} D_{z}^{i} / z_{i}$ is sufficiently small (see Appendix A). Yet in general, the sign of $\mathrm{d} u_{i} / \mathrm{d} t_{y}$ is ambiguous for permit-exporting countries as well as for permit-importing countries. It crucially depends on the sign and magnitude of $\mathrm{d} \pi_{e} / \mathrm{d} t_{y}$ the specification of which requires to explore how the permit market responds to variations in the tax rate $t_{y}$. Since the permit market is at the core of the EU-style emissions control we will investigate the determinants of $\mathrm{d} \pi_{e} / \mathrm{d} t_{y}$ in more detail.

Observe first that in the initial equilibrium the equations (6) and (11) hold so that the clearance of the permit market can be expressed by

$$
\sum_{j}\left[E^{x j}\left(p_{x j}, q_{e}\right)+E^{y j}\left(q_{e}\right)\right]=\sum_{j} c_{j}
$$

where $q_{e}:=p_{e}+\pi_{e}+t_{y}$, and where $E^{x i}(\cdot)$ and $E^{y i}(\cdot)$ are sectoral demand functions for energy and permits implicitly contained in (11). If in (17) the prices $p_{x 1}, \ldots, p_{x n}$ clear the national markets for good $X$, equation (17) determines the equilibrium permit price, $\pi_{e}$, for some given $t_{y}$. Differentiating (17) with respect to $t_{y}$ yields, after some rearrangement of terms,

$$
\frac{\mathrm{d} \pi_{e}}{\mathrm{~d} t_{y}}=-1-\frac{\sum_{j}\left(E_{p_{x j}}^{x j} \frac{\mathrm{d} p_{x j}}{\mathrm{~d} t_{y}}\right)}{\sum_{j}\left(E_{q_{e}}^{x j}+E_{q_{e}}^{y j}\right)}=-1+\frac{\sum_{j}\left(\alpha_{j} \frac{\mathrm{d} p_{x j}}{\mathrm{~d} t_{y}}\right)}{\sum_{j} \beta_{j}} .
$$

According to (18) changes in the tax rate $t_{y}$ are exactly offset by opposite changes in the permit price $\pi_{e}$ unless $\sum_{j}\left[\alpha_{j}\left(\mathrm{~d} p_{x j} / \mathrm{d} t_{y}\right)\right] \neq 0$. This term is clearly zero in partial equilibrium models where $Y$ is the only consumer good. However, in market economies with more than one consumer good, the interdependence effects $\mathrm{d} p_{x i} / \mathrm{d} t_{y}$ will lead to $\mathrm{d} \pi_{e} / \mathrm{d} t_{y} \neq$ -1 , in general. In Appendix A these interdependence effects are calculated as

$$
\frac{\mathrm{d} p_{x i}}{\mathrm{~d} t_{y}}=\frac{\delta_{i}+\Delta e_{y i} D_{z}^{i}}{\gamma_{i}} \frac{\mathrm{d} \pi_{e}}{\mathrm{~d} t_{y}}+\frac{\delta_{i}}{\gamma_{i}}
$$

From inserting (19) into (18) follows, after some rearrangement of terms,

$$
\frac{\mathrm{d} \pi_{e}}{\mathrm{~d} t_{y}}=-\frac{1}{1+\frac{\sum_{j} \frac{\alpha_{j} D_{z}^{j}}{\gamma_{j}} \Delta e_{y j}}{\sum_{j} \frac{\alpha_{j}{ }_{j}{ }^{j}-\beta_{j} \gamma_{j}}{\gamma_{j}}}} .
$$


Not surprisingly, (20) allows for deviations of $\mathrm{d} \pi_{e} / \mathrm{d} t_{y}$ from -1 in either direction as does (18). However, closer inspection of (20) shows that progress can be made in the special case of utility functions taking on the functional form $U^{i}\left(x_{i}, y_{i}\right)=V^{i}\left(x_{i}\right)+y_{i}$ with $V^{i}$ being increasing and strictly concave in $x_{i}$. For that class of so-called quasi-linear utility functions the income effect of the demand for good $X$ is known to be zero $\left(D_{z}^{i} \equiv 0\right)$ such that $(20)$ turns into $\mathrm{d} \pi_{e} / \mathrm{d} t_{y}=-1$.

\section{Proposition 2.}

If the utility functions $U^{i}$ from (2) are quasi-linear the incidence of the emissions tax is given by Table 3.

\begin{tabular}{|c||c|c|c|c|c|c|c|c|c|}
\hline & $\mathrm{d} \pi_{e}$ & $\mathrm{~d} p_{x i}$ & $\mathrm{~d} e_{y i}$ & $\mathrm{~d} e_{x i}$ & $\mathrm{~d} \Delta e_{y i}$ & $\mathrm{~d} x_{i}$ & $\mathrm{~d} y_{i}$ & $\mathrm{~d} z_{i}$ & $\mathrm{~d} u_{i}$ \\
\hline \hline $\mathrm{d} t_{y}, \Delta e_{y i}>0$ & -1 & 0 & 0 & 0 & 0 & 0 & - & - & - \\
\hline $\mathrm{d} t_{y}, \Delta e_{y i}<0$ & -1 & 0 & 0 & 0 & 0 & 0 & + & + & + \\
\hline
\end{tabular}

Table 3: Tax incidence in the general model in case of quasi-linear utility functions

It is easy to see that with $D_{z}^{i}=0$ (all $i$ ) the ETS and the overlapping (uniform) emissions tax are perfect substitutes in the sense that the total factor price, $q_{e}=p_{e}+\pi_{e}+t_{y}$, is unaffected by variations in $t_{y}$. Since $D_{z}^{i}=0$ and since $\mathrm{d} \pi_{e} / \mathrm{d} t_{y}$ eliminates spillovers between the permit market and the national markets for good $X$, the demand for permit remains unchanged in all sectors and hence the permit market is unaffected. However, the distributional incidence of tax shifts is pronounced: An increase in the tax rate $t_{y}$ benefits permit-importing countries but reduces the welfare of permit-exporting countries. Since $\mathrm{d} e_{x i}=\mathrm{d} e_{y i}=0, \mathrm{~d}\left(\Delta e_{y i}\right) / \mathrm{d} t_{y i}=0$ follows, i.e. a country's permit exports or imports do not depend on the level of $t_{y}$.

Zero income elasticity of demand for good $X$ appears to be a restrictive and unrealistic assumption. As pointed out above it eliminates market-interdependence effects and thus "isolates" the permit market which can then be studied as in a partial equilibrium model. To gain further insights in the tax incidence without assuming zero income effects we will resort to parametric functional forms of the Cobb-Douglas type.

\subsection{Comparative statics using parametric functional forms}

We now parametrize the model by introducing the Cobb-Douglas utility functions

$$
U^{i}\left(x_{i}, y_{i}\right)=x_{i}^{h_{i}} y_{i}^{1-h_{i}}, \quad X^{i}\left(e_{x i}\right)=e_{x i}^{a_{i}}, \quad Y^{i}\left(e_{y i}\right)=e_{y i}^{b_{i}}
$$


With (21) the impact of variations in the tax rate $t_{y}$ on the permit price, $\pi_{e}$, can be shown (Appendix B) to be

$$
\frac{\mathrm{d} p_{x i}}{\mathrm{~d} t_{y}}=\kappa_{i} \Delta e_{y i} \frac{\mathrm{d} \pi_{e}}{\mathrm{~d} t_{y}}+\mu_{i}\left(1+\frac{\mathrm{d} \pi_{e}}{\mathrm{~d} t_{y}}\right)
$$

where $\kappa_{i}:=\frac{\left(1-a_{i}\right) p_{x i} a_{i}}{e_{x i}\left[\left(p_{e}+\pi_{e}\right) a_{i}+\bar{h}_{i} q_{e}\right]}>0, \bar{h}_{i}:=\frac{\left(1-h_{i}\right)}{h_{i}}>0, \mu_{i}:=\rho_{i} p_{x i}\left[\frac{\bar{h}_{i} q_{e}+a_{i}\left(p_{e}+\pi_{e}\right)}{a_{i} q_{e}}-\frac{\left(1-a_{i}\right)}{e_{x i}}\right](\gtreqless 0)$ and $\rho_{j}:=\frac{a_{i}}{\left(p_{e}+\pi_{e}\right) a_{i}+h_{i} q_{e}}>0$. According to $(22), \mathrm{d} p_{x} / \mathrm{d} t_{y} \neq 0$ is non-zero in general, and this is true even in case of $\mathrm{d} \pi_{e} / \mathrm{d} t_{y}=-1 .{ }^{10}$ More specifically, for $\mathrm{d} \pi_{e} / \mathrm{d} t_{y}=-1$ it follows from (22) that $\mathrm{d} p_{x i} / \mathrm{d} t_{y}>0$ for permit-importing countries and $\mathrm{d} p_{x i} / \mathrm{d} t_{y}<0$ for permit-exporting countries. If $\mathrm{d} \pi_{e} / \mathrm{d} t_{y} \neq-1, \mathrm{~d} p_{x i} / \mathrm{d} t_{y}$ may be positive or negative.

Inserting (22) into (18) does not render the result more informative. However, taking another route of comparative static calculations (Appendix B) we find

$$
\frac{\mathrm{d} \pi_{e}}{\mathrm{~d} t_{y}}=-\frac{1}{1-\frac{\sum_{j} \rho_{j} \Delta e_{y j}}{\sum_{j} \rho_{j} \sigma_{j}}},
$$

where $\sigma_{i}:=\frac{\bar{h}_{i} e_{x i}}{a_{i}}+\frac{\left(\bar{h}_{i}+a_{i}\right) e_{y i}}{\left(1-b_{i}\right) a_{i}}>0$. As in the model of Section 3.1, the change in the countries' welfare, $\mathrm{d} u_{i} / \mathrm{d} t_{y}$, is given by (16). $\mathrm{d} u_{i} / \mathrm{d} t_{y}$ remains ambiguous in sign although $\gamma_{i}$ is now unequivocally positive. However, closer inspection of (23) reveals that $\mathrm{d} \pi_{e} / \mathrm{d} t_{y}=-1$, if

$$
a_{i}=a \quad \text { and } \quad h_{i}=h \quad \text { for all } i .
$$

Note that with (24) countries may still differ with respect to their production functions for $\operatorname{good} Y\left(b_{i} \neq b_{j}\right)$ and their national caps $\left(c_{i} \neq c_{j}\right)$ such that net exports and imports of permits will be non-zero, in general.

A remarkable consequence of the assumption (24) is that in contrast to the special case $D_{z}^{i}=0$, all $i$, of Section 3.1 variations in $t_{y}$ do affect the market for good $X$ : Combining (22) and (24) shows that a tax hike $\mathrm{d} t_{y}>0$ will raise [lower] the equilibrium price $p_{x i}$ if country $i$ imports [exports] permits. Moreover, we know from comparing (18) and (23) that if (24) holds the opposite price changes of permit exporting and importing countries are symmetric in the sense that $\sum_{j}\left[\alpha_{j}\left(\mathrm{~d} p_{x j} / \mathrm{d} t_{y}\right)\right]=0$.

Since $q_{e}$ remains unchanged, the demand for energy inputs of the ETS sectors does not change either. On the other hand, the increase [reduction] in the price $p_{x i}$ induced by $\mathrm{d} t_{y}>0$ reduces [increases] the demand for energy inputs in the non-ETS sector of permit exporting [importing] countries such that exports as well as imports rise. Since it can be shown that

$$
\lim _{\Delta e_{y i} \rightarrow 0} \frac{\mathrm{d} \Delta e_{y i}}{\mathrm{~d} t_{y}}=0
$$

\footnotetext{
${ }^{10}$ Recall that in the previous section $D_{z}^{i}=0$ for all $i$ implied $\mathrm{d} \pi_{e} / \mathrm{d} t_{y}=-1$ as well as $\mathrm{d} p_{x i} / \mathrm{d} t_{y}=0$. Note also that with the Cobb-Douglas utility function the income effect on the demand for both goods is positive.
} 
we conclude that the subsets of permit-exporting and importing countries are independent of the level of $t_{y}$. The comparative statics carried out in Appendix B yield

\section{Proposition 3.}

If the functions $X^{i}, Y^{i}$ and $U^{i}$ from (1) and (2) are specified by (21) and if (24) holds, the incidence of the emissions tax is given by Table 4.

\begin{tabular}{|c||c|c|c|c|c|c|c|c|c|}
\hline & $\mathrm{d} \pi_{e}$ & $\mathrm{~d} p_{x i}$ & $\mathrm{~d} e_{y i}$ & $\mathrm{~d} e_{x i}$ & $\mathrm{~d} \Delta e_{y i}$ & $\mathrm{~d} x_{i}$ & $\mathrm{~d} y_{i}$ & $\mathrm{~d} z_{i}$ & $\mathrm{~d} u_{i}$ \\
\hline \hline $\mathrm{d} t_{y}, \Delta e_{y i}>0$ & -1 & - & 0 & - & + & - & - & - & - \\
\hline $\mathrm{d} t_{y}, \Delta e_{y i}<0$ & -1 & + & 0 & + & - & + & + & + & + \\
\hline
\end{tabular}

Table 4: Tax incidence in the parametric model, when technologies of good $X$ and preferences are the same across countries

Comparing Table 4 with Table 3 reveals that in both cases we observe $\mathrm{d} \pi_{e} / \mathrm{d} t_{y}=-1$ and the qualitative changes in $\mathrm{d} e_{y i}, \mathrm{~d} y_{i}, \mathrm{~d} z_{i}$ and $\mathrm{d} u_{i}$ are the same. However, while in case of $D_{z}^{i} \equiv 0$ (Table 3) both endogenous markets, i.e. the market for good $X$ and the permit market, remain unaffected, the parametric model satisfying (24) exhibits repercussions in both markets. As an implication, the cost-effective split of the national emissions caps into two sectoral caps depends on the level of the tax rate $t_{y}$ in the parametric model satisfying (24) while it is unaffected by $t_{y}$ in case of $D_{z}^{i}=0$.

Apart from these differences, the restrictions imposed on the model in Propositions 2 and 3 have an important property in common: They imply that the derivatives of all endogenous variables with respect to $t_{y}$ are either zero or unconditionally positive or negative. In other words, there are functions $v=v\left(t_{y}\right)$ for all endogenous variables $v=\pi_{e}, p_{x i}, e_{x i}, e_{y i}, \Delta e_{y i}, x_{i}, y_{i}, z_{i}, u_{i}$ which are monotone or strictly monotone in the tax rate $t_{y}$. For that reason the comparative statics analysis does not only yield 'local information' for marginal variations in the tax rate but provides 'global information' about the properties of the functions $v=v\left(t_{y}\right)$. The most relevant properties are highlighted in

\section{Proposition 4.}

Denote by $\Delta e_{y i}\left(t_{y}\right)$ and $u_{i}\left(t_{y}\right)$ country $i$ 's permit trade balance and welfare, respectively, when the center has fixed the tax rate at $t_{y} \in\left[0, \bar{t}_{y}\right]$ and suppose the functional forms are as specified in Proposition 2 or Proposition 3.

(a) If country $i$ exports [imports] permits for some $t_{y} \in\left[0, \bar{t}_{y}\right]$, it exports [imports] permits for all $t_{y} \in\left[0, \bar{t}_{y}\right]$.

(b) Permit-exporting [permit-importing] countries lose [gain] whenever the tax rate $t_{y}$ is 
raised such that

$$
u_{i}(0)>u_{i}\left(\bar{t}_{y}\right) \text {, if } \Delta e_{y i}>0 \text { and } u_{i}(0)<u_{i}\left(\bar{t}_{y}\right) \text {, if } \Delta e_{y i}<0 \text {. }
$$

We conclude that under the conditions of Proposition 4 the distributional consequences of variations in the tax rate $t_{y}$ are unambiguous. Unfortunately this feature does not hold in general, i.e. if $D_{z}^{i} \neq 0$ or if (24) does not hold, we cannot draw conclusions from marginal information provided by the comparative-static analysis on the global properties of the functions $v\left(t_{y}\right)$. In the next Section we will therefore resort to numerical analysis of our parametric model aiming at global information on the functions $v\left(t_{y}\right)$ when $(24)$ is not satisfied. Particular attention will be placed on whether and how $\mathrm{d} \pi_{e} / \mathrm{d} t_{y}$ deviates from minus one, whether non-marginal variations of $t_{y}$ may lead to export-import reversals and what the associated changes in the distribution of national welfare are.

\subsection{Non-monotone changes in welfare: a numerical example}

In this section we consider a parametric model of Section 3.2 for which condition (24) is not satisfied. To make progress we consider a three-country model in which the parameters take on the values $a_{1}=0.2, a_{2}=0.6, a_{3}=0.9, b_{1}=b_{2}=b_{3}=0.5, c_{1}=0.605, c_{2}=0.6$, $c_{3}=1.3, h_{1}=h_{2}=h_{3}=0.5, p_{e}=0.2$. For this model we then compute the equilibrium allocation as a function of the tax rate $t_{y}$ with the help of the tool Mathematica (Appendix C) establishing

\section{Proposition 5.}

If in the parametric model of Section 3.2 the tax rate $t_{y}$ is successively raised, some permitexporting country may eventually import permits such that its national income and welfare first decline but then increase.

The qualitative properties of the response of the entire equilibrium allocation to successive increases in the tax rate are summarized in Table 5, and the Figures 1, 2 and 3 provide additional illustration of some of the particularly interesting functions.

\begin{tabular}{|c|c|c|c|c|c|c|c|}
\hline & $\pi_{e}\left(t_{y}\right)$ & $p_{x i}\left(t_{y}\right)$ & $e_{y i}\left(t_{y}\right)$ & $e_{x i}\left(t_{y}\right)$ & $\Delta e_{y i}\left(t_{y}\right)$ & $x_{i}\left(t_{y}\right)$ & $y_{i}\left(t_{y}\right) \quad z_{i}\left(t_{y}\right) \quad u_{i}\left(t_{y}\right)$ \\
\hline country 1 & \multirow{6}{*}{ DECR } & $\mathrm{U}-\mathrm{SH}$ & \multirow{6}{*}{$\begin{array}{c}\text { INCR } \\
\& \\
\mathrm{CONV}\end{array}$} & \multirow{4}{*}{$\begin{array}{l}\text { INCR } \\
\text { CONV }\end{array}$} & DECR & \multirow{4}{*}{$\begin{array}{l}\text { INCR } \\
\text { CONV }\end{array}$} & \multirow{2}{*}{ U-SH \& CONV } \\
\hline$\Delta e_{y 1} \gtrless 0$ & & $\mathrm{CONV}$ & & & CONC & & \\
\hline country 2 & & INCR & & & DECR & & \multirow{2}{*}{ INCR \& CONV } \\
\hline$\Delta e_{y 2}<0$ & & $\mathrm{CONV}$ & & & CONV & & \\
\hline country 3 & & DECR & & DECR & INCR & DECR & \multirow{2}{*}{ DECR \& CONV } \\
\hline$\Delta e_{y 3}>0$ & & $\mathrm{CONC}$ & & CONC & CONV & CONC & \\
\hline
\end{tabular}


$(\mathrm{DECR}=$ monotone decreasing, $\mathrm{U}-\mathrm{SH}=\mathrm{u}$-shaped, $\mathrm{INCR}=$ monotone increasing, $\mathrm{CONV}=$ strictly convex, $\mathrm{CONC}=$ strictly concave)

Table 5: Equilibrium quantities and prices as functions of the tax rate $t_{y}$ : numerical example
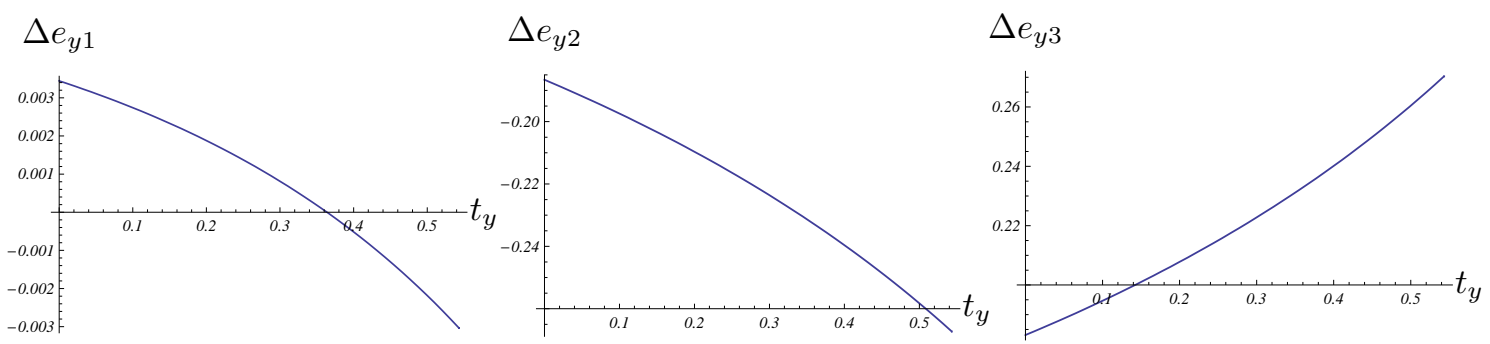

Figure 1: Exports and imports of permits

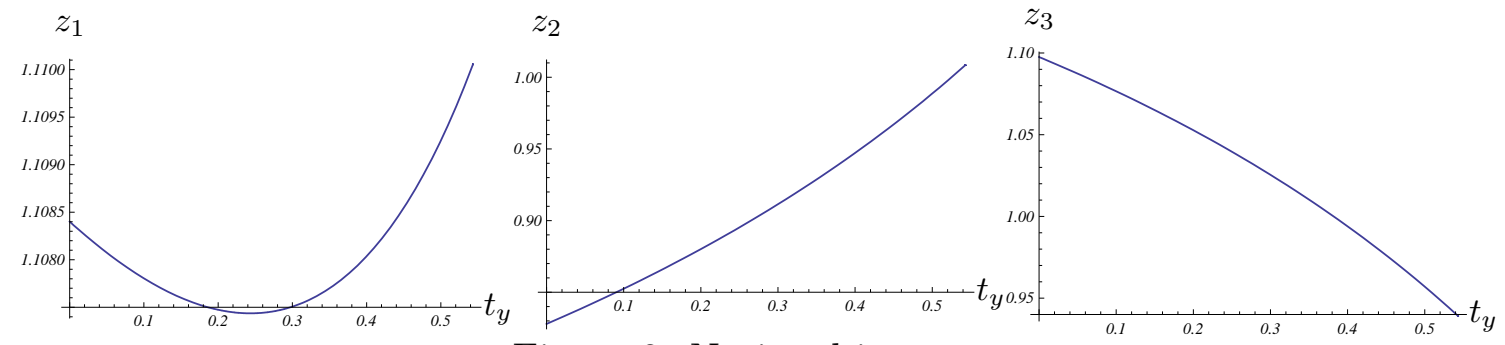

Figure 2: National incomes
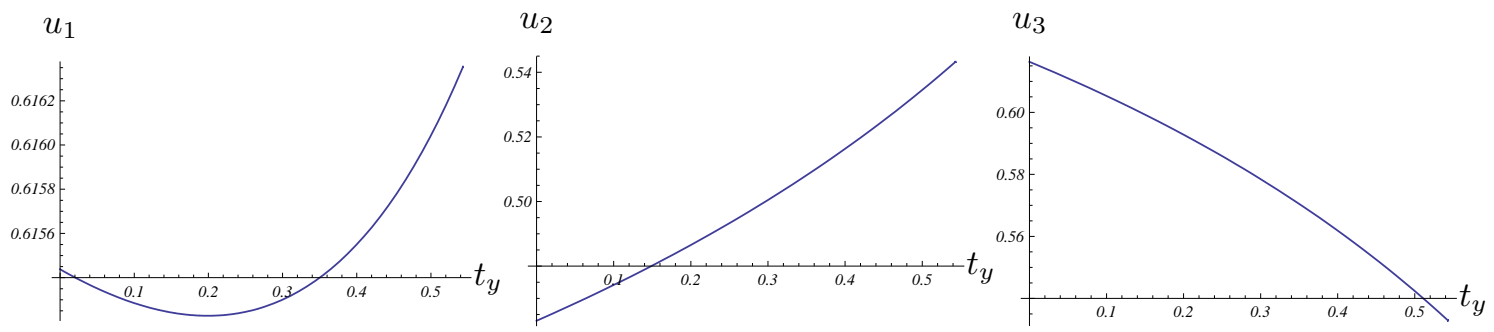

Figure 3: National welfare

A few comments on the results are in order. Although the graph of the function $\pi_{e}\left(t_{y}\right)$ (see Appendix C) is clearly negatively sloped it exhibits little curvature, if any. Nonetheless we safely conclude that $\mathrm{d} \pi_{e} / \mathrm{d} t_{y}<-1$ because $e_{y i}\left(t_{y}\right)=\left(\frac{p_{e}+\pi_{e}+t_{y}}{b_{i}}\right)^{\frac{1}{b_{i}-1}}$ is obviously strictly increasing in $t_{y}$ for $i=1,2,3$ and hence

$$
\frac{\mathrm{d} e_{y i}}{\mathrm{~d} t_{y}}=-\frac{e_{y i}}{\left(1-b_{i}\right) q_{e}}\left(\frac{\mathrm{d} \pi_{e}}{\mathrm{~d} t_{y}}+1\right) .
$$


Country 2 imports and country 3 exports permits, and as in the model of Table 4 the levels of imports and exports rise with increasing tax rate (Figure 2). Corresponding to these changes the national income and the welfare in country 2 increase with the tax rate while national income and welfare shrink in country 3 (Figures 2 and 3).

The striking feature of the numerical example under consideration highlighted in Proposition 5 are the effects of successive tax increases on the allocation in country 1 . As shown in the left panel of Figure 1 country 1 first exports permits but becomes an importer of permits when the tax continues to increase. ${ }^{11}$ Along with that reversal from exports to imports the price of good $X$, the national income and national welfare of country 1 are $\mathrm{u}$-shaped functions of the tax rate (left panels of Figures 2 and 3). The observation that export-import reversals are feasible and with them non-monotone welfare changes makes it difficult to assess correctly the impact of tax hikes on the international distribution of welfare.

\section{Emissions tax incidence in simplified models}

It is clearly the EU-type emissions control as modeled above that is crucial for our result that national welfare may be non-monotone in the tax rate $t_{y}$ (Proposition 5). To further clarify and reinforce that observation we will show in the sequel that non-monotone welfare changes do not occur in modified versions of our standard model in which either the international ETS is replaced by disjoined national ETSs or in which all national economies consist of one sector only. In Section 4.1 we investigate two-sector economies with domestic ETS and in Section 4.2 we turn to one-sector economies with international ETS.

\subsection{Two-sector economies with domestic ETSs}

We now assume that the group of countries does not achieve its emissions target $\sum_{j} c_{y i}$ through an international ETS but that in each country a domestic ETS is in operation such that the emissions in country $i$ 's sector $Y$ are restrained by

$$
c_{y i}=e_{y i}
$$

\footnotetext{
${ }^{11}$ The same qualitative result is obtained by Böhringer et al. (2007) in their CGE approach for the case that an overlapping tax is unilaterally levied by one of the EU member states. However, that policy not only places an excess cost on the country levying an overlapping tax but it also is cost-ineffective from the point of view of the group of countries. In the present paper we focus on variations in an overlapping tax that is uniform across countries and hence does compromise cost-effectiveness.
} 
The two-sector model with domestic ETS is specified by (1) - (5) and (26), and the country's trade balance is given by

$$
p_{y}\left(y_{s j}-y_{j}\right)-p_{e}\left(e_{x j}+e_{y j}\right)=0
$$

Profit maximization implies (11) and the consumer's budget and demand function are given by (12) and (13), respectively. Without loss of generality we restrict our attention to a representative country and suppress the index $i$. Then the cost-effective allocation follows from solving the Lagrangian

$$
\begin{aligned}
\mathcal{L} & =U(x, y)+\lambda_{x}\left[X\left(e_{x}\right)-x\right]+\lambda_{c}\left(c-c_{y}-e_{x}\right) \\
& +\lambda_{h}\left\{p_{y}\left[Y\left(e_{y}\right)-y\right]-p_{e}\left(e_{x}+e_{y}\right)\right\}+\lambda_{e}\left(c_{y}-e_{y}\right)
\end{aligned}
$$

It is straightforward to show that the competitive equilibrium of an individual two-sector economy with domestic ETS is cost-effective if and only if $t_{x}=\mu_{e}, t_{y} \in\left[0, \mu_{e}\right]$ and $\pi_{e}=$ $\mu_{e}-t_{y}$, where $\mu_{e}:=\lambda_{e} / \lambda_{h}$. As in the previous section cost-effectiveness can be achieved by levying an emissions tax in sector $X$ in combination either with an emissions tax in sector $Y$, or with a pure domestic ETS, or with intermediate policies combining positive tax rates $t_{y}>0$ with an ETS. ${ }^{12}$

The comparative statics in Appendix D of parametric changes in $t_{y}$ reveal

Proposition 6. Consider a group of countries each of which consists of a two-sector economy and operates a domestic ETS. For such country it is true that

(i) an increase in the emissions tax rate $t_{y}$ is exactly offset by a reduction in the equilibrium permit price $\left(\mathrm{d} \pi_{e}=-\mathrm{d} t_{y}\right)$;

(ii) the cost-effective allocation and the country's welfare are unaffected by small variations in the emissions tax rate $t_{y}$.

Proposition 6 highlights the distributional irrelevance of variations in $t_{y}$ in the simple economy under consideration. Because the emissions controls of the countries are independent, neither the ETS-only policy nor the tax-only policy nor any policy mix has allocative or distributional displacement effects.

\footnotetext{
${ }^{12}$ Note that tax rates will tend to differ across countries in the model under consideration because the countries' emissions controls are no longer interdependent. As a consequence, the overall cap $\bar{c}=\sum_{j} c_{j}$ is not implemented in a cost-effective way, in general, although each country's emissions control is costeffective from the country's domestic perspective.
} 


\subsection{One-sector economies with international ETS}

In this subsection we deviate from our standard model by assuming that the economy of country $i$ consists only of a single sector, sector $Y$. Carrying over the notation from the standard model, the model in the present section is given by

$$
\begin{array}{r}
y_{s i}=Y^{i}\left(e_{y i}\right), \\
u_{i}=U^{i}\left(y_{i}\right), \\
\bar{c}=\sum_{j} c_{j}=\sum_{j} e_{y j}, \\
\sum_{j}\left[p_{y}\left(y_{s j}-y_{j}\right)-p_{e} e_{y j}\right]=0, \\
p_{y} Y_{e}^{i}=\pi_{e}+t_{y i}+p_{e}, \\
z_{i}=p_{y} y_{i} .
\end{array}
$$

(29) and (30) specify the production and utility function, respectively. The market for emissions clears according to (31). (32) is the group's consolidated trade balance, (33) is the aggregate firm's first-order condition of profit maximization and (34) is the consumer's budget constraint.

Determining the cost-effective allocation and decentralizing it in a competitive economy we obtain a special case of Proposition 1 where $t_{x i}=0$ for all $i$, which is obvious since we eliminated sector $X$. In a group of countries with international ETS a precondition for cost-effectiveness is an emissions tax $t_{y}$ being uniform across countries. Again we get an equivalence regarding cost-effectiveness of the ETS-only policy, the tax-only policy and all "convex combinations". However, unlike in the model of the previous section, variations in the tax rate now do have allocative and distributional effects. To obtain more specific qualitative information on those effects, we investigate the impacts of parametric changes in $t_{y}$ on cost-effective competitive equilibria in comparative static analysis (Appendix D). The results are summarized in

Proposition 7. Consider a group of countries each of which consists of a one-sector economy and all countries operate a joint ETS. The incidence of small variations in the uniform emissions tax is given by

\begin{tabular}{|c|c|c|c|c|c|c|}
\hline & $\mathrm{d} \pi_{e}$ & $\mathrm{~d} e_{y i}$ & $\mathrm{~d} \Delta e_{y i}$ & $\mathrm{~d} y_{i}$ & $\mathrm{~d} z_{i}$ & $\mathrm{~d} u_{i}$ \\
\hline \hline $\mathrm{d} t_{y}, \Delta e_{y i}>0$ & -1 & 0 & 0 & - & - & - \\
$\mathrm{d} t_{y}, \Delta e_{y i}<0$ & -1 & 0 & 0 & + & + & + \\
\hline
\end{tabular}

Table 6: Tax incidence in one-sector economies; $\Delta e_{y i}:=c_{i}-e_{y i}$ 
From Proposition 7 we infer that an increase in the tax rate $t_{y}$ is exactly offset by a reduction in the permit price $\left(\mathrm{d} \pi_{e} / \mathrm{d} t_{y}=-1\right)$ thus leaving the firms' production and input decisions unaffected $\left(\mathrm{d} y_{s i} / \mathrm{d} t_{y}=\mathrm{d} e_{y i} / \mathrm{d} t_{y}=0\right)$. Therefore the change in the consumer's income is given by

$$
\mathrm{d} z_{i}=\mathrm{d} y_{i}=\Delta e_{y i} \mathrm{~d} \pi_{e}
$$

where $\Delta e_{y i}:=c_{i}-e_{y i}$ is the amount of permits exported $\left(\Delta e_{y i}>0\right)$ or imported $\left(\Delta e_{y i}<0\right)$ by country $i$. According to (35) increasing $t_{y}$ reduces the permit-exporting country's income. As an immediate consequence, the consumption of good $Y$ declines and with it the country's welfare. All these effects are reversed in permit-importing countries.

To sum up, allocative and distributional effects vanish altogether if economies have two sectors but ETS is domestic. Furthermore, one-sector economies with international ETS exhibit the same allocative and distributional effects as two-sector economies with international ETS and quasi-linear utility functions. It follows that a necessary condition for non-monotone welfare changes is an EU-type emissions control in the sense that an international ETS is established in a group of countries such that only some part of all countries' economies is covered by the ETS.

\section{Concluding remarks}

In a stylized way, our paper addresses distributional consequences of a hybrid regime of $\mathrm{CO}_{2}$ emissions control designed to capture the basic features of the regime applied in the EU since 2005. Characteristic of the EU regime is an EU-wide international ETS that coexists with national complementary and overlapping national emissions taxes. Restricting our attention to cost-effective competitive equilibria we show that an increase in the rate of the emissions tax levied in the ETS sector is exactly offset by a reduction in the equilibrium permit price in the case of quasi-linear utility functions and for a class of parametric utility and production functions. Since the reduction in the permit price lowers [raises] a permitexporting [importing] country's income, permit-exporting [importing] countries lose [gain] from an increase in the emissions tax. However, these results are not general, because emissions tax changes may cause ramifications beyond the permit market. With the help of a numerical example we show that an initially permit-exporting country may switch to import permits when the emissions tax is successively increased. Hence, export-import reversals are feasible such that initially welfare-losing countries may turn to welfare-gaining countries and vice versa. 


\section{References}

Böhringer, C., Koschel, H. and U. Moslener (2007), Efficiency losses from overlapping economic instruments in European carbon emissions regulation, Journal of Regulatory Economics, DOI 10.1007/S11149-007-9054-8.

Eichner, T. and R. Pethig (2008): $\mathrm{CO}_{2}$ emissions control with national emissions taxes and an international emissions trading scheme, discussion paper.

EU (1999): Preparing implementation of the Kyoto Protocol, COM (1999) 230.

EU (2000): Green paper on greenhouse gas emissions trading within the European Union, COM (2000) 87 final (presented by the Commission).

EU (2003a): Council Directive 96/61/EC, establishing a scheme for greenhouse gas emission allowance within the community and amending, European Commission, Brussels.

EU (2003b): Council Directive 2003/96/EC of 27 October 2003 restructuring the taxation of energy products and electricity, European Commission, Brussels.

International Energy Agency (2007): Energy prices and taxes. Quarterly Statistics: Third Quarter 2007.

Johnstone, (2003): The use of tradable permits in combination with other environmental policy instruments, Report ENV/EPOC/WPNEP (2002)28/FINAL, OECD, Paris.

Shiell, L. (2003): Equity and efficiency in international markets for pollution permits, Journal of Environmental Economics and Management 46 (2003), 38-51.

Sorell, S. and J. Sijm (2003): Carbon trading in the policy mix, Oxford Review of Economic Policy 19, 420-437. 


\section{Appendix A: Comparative statics of the general model}

The cost-effective competitive equilibrium of the multi-country economy is completely described by the following equations:

$$
\begin{array}{ll}
\sum_{j} c_{j}=\sum_{j}\left(e_{x j}+e_{y j}\right), & \\
x_{s i}=x_{i}, & i=1, \ldots, n, \\
x_{s i}=X^{i}\left(e_{x i}\right), & i=1, \ldots, n, \\
x_{i}=D^{i}\left(p_{x i}, z_{i}\right), & i=1, \ldots, n, \\
z_{i}=p_{x i} x_{i s}+y_{i s}-p_{e}\left(e_{x i}+e_{y i}\right)+\pi_{e}\left(c_{i}-e_{x i}-e_{y i}\right), \quad i=1, \ldots, n \\
y_{s i}=Y^{i}\left(e_{y i}\right), & i=1, \ldots, n, \\
z_{i}=p_{x i} x_{i}+y_{i}, & i=1, \ldots, n, \\
p_{x i} X_{e}^{i}\left(e_{x i}\right)=p_{e}+t_{x}, & i=1, \ldots, n, \\
Y_{e}^{i}=p_{e}+\pi_{e}+t_{y}, & i=1, \ldots, n, \\
t_{x}=\pi_{e}+t_{y}, &
\end{array}
$$

where without loss of generality good $Y$ is chosen as numeraire $\left(p_{y} \equiv 1\right)$. The variables determined by (A1) - (A10) are $e_{x i}, e_{y i}, x_{s i}, x_{i}, p_{x i}, z_{i}, y_{s i}, y_{i}$ for $i=1, \ldots, n, \pi_{e}$ and $t_{x}$. The tax rate $t_{y}$ is treated here as an exogenous parameter. It is convenient to compress the system of equations (A1) - (A10) as follows:

$$
\begin{aligned}
& \sum_{j} c_{j}=\sum_{j}\left(e_{x j}+e_{y j}\right), \\
& X^{i}\left(e_{x i}\right)=D^{i}\left(p_{x i}, z_{i}\right), \\
& z_{i}=p_{x i} X^{i}\left(e_{x i}\right)+Y^{i}\left(e_{y i}\right)-p_{e}\left(e_{x i}+e_{y i}\right)+\pi_{e} \Delta e_{y i}, \\
& p_{x i} X_{e}^{i}\left(e_{x i}\right)=Y_{e}^{i}\left(e_{y i}\right), \\
& Y_{e}^{i}\left(e_{y i}\right)=p_{e}+\pi_{e}+t_{y}, \\
& y_{i}=Y^{i}\left(e_{y i}\right)-p_{e}\left(e_{x i}+e_{y i}\right)+\pi_{e} \Delta e_{y i},
\end{aligned}
$$

where $\Delta e_{y i}:=c_{i}-e_{x i}-e_{y i}$ in (A13) is the amount of permits exported or imported by country $i$. The equations (A11) - (A15) serve to determine $\pi_{e}$ and $e_{x i}, e_{y i}, p_{x i}$ and $z_{i}$ for $i=1, \ldots, n$. Equation (A16) represents the current account balances, and it determines $y_{i}$ after $e_{x i}, e_{y i}$ and $\pi_{e}$ are solved via (A11) - (A15). Our aim is to perform a comparative static analysis to specify the impact on the economy of exogenous variations in the uniform 
tax rate $t_{y}$. To that end (A11) through (A15) are now totally differentiated.

$$
\begin{aligned}
& \sum_{j} \mathrm{~d} e_{x j}+\sum_{j} \mathrm{~d} e_{y j}=0 \\
& X_{e}^{i} \mathrm{~d} e_{x i}-D_{p}^{i} \mathrm{~d} p_{x i}-D_{z}^{i} \mathrm{~d} z_{i}=0 \\
& \mathrm{~d} z_{i}=x_{i} \mathrm{~d} p_{x i}+t_{y}\left(\mathrm{~d} e_{x i}+\mathrm{d} e_{y i}\right)+\Delta e_{y i} \mathrm{~d} \pi_{e}, \\
& X_{e}^{i} \mathrm{~d} p_{x i}+p_{x i} X_{e e}^{i} \mathrm{~d} e_{x i}-Y_{e e}^{i} \mathrm{~d} e_{y i}=0 \\
& Y_{e e}^{i} \mathrm{~d} e_{y i}-\mathrm{d} \pi_{e}-\mathrm{d} t_{y}=0
\end{aligned}
$$

To obtain (A19) we have differentiated (A13),

$$
\mathrm{d} z_{i}=x_{s i} \mathrm{~d} p_{x i}+p_{x i} X_{e}^{i} \mathrm{~d} e_{x i}+Y_{e}^{i} \mathrm{~d} e_{y i}-p_{e}\left(\mathrm{~d} e_{x i}+\mathrm{d} e_{y i}\right)+\Delta e_{y i} \mathrm{~d} \pi_{e}-\pi_{e}\left(\mathrm{~d} e_{x i}+\mathrm{d} e_{y i}\right),
$$

and then made use of (A14) and (A15).

Next we consider $\mathrm{d} e_{y i}=\frac{1}{Y_{e e}^{i}}\left(\mathrm{~d} \pi_{e}+\mathrm{d} t_{y}\right)$ from (A21) in (A20) to obtain

$$
\mathrm{d} e_{x i}=\frac{1}{p_{x i} X_{e e}^{i}}\left(\mathrm{~d} \pi_{e}+\mathrm{d} t_{y}\right)-\frac{X_{e}^{i}}{p_{x i} X_{e e}^{i}} \mathrm{~d} p_{x i} .
$$

Summation of $\mathrm{d} e_{x i}$ from (A22) and d $e_{y i}$ from (A21) yields

$$
\mathrm{d} e_{x i}+\mathrm{d} e_{y i}=\alpha_{i} \mathrm{~d} p_{x i}-\beta_{i}\left(\mathrm{~d} \pi_{e}+\mathrm{d} t_{y}\right)
$$

where $\alpha_{i}:=-\frac{X_{e}^{i}}{p_{x i} X_{e e}^{i}}>0$ and $\beta_{i}:=-\left(\frac{1}{Y_{e e}^{i}}+\frac{1}{p_{x i} X_{e e}^{i}}\right)>0$. Inserting (A23) in (A17) gives

$$
\frac{\sum_{j} \alpha_{j} \mathrm{~d} p_{x j}}{\sum_{j} \beta_{j}}-\mathrm{d} \pi_{e}=\mathrm{d} t_{y} .
$$

We take advantage of (A23) to turn (A19) into

$$
\mathrm{d} z_{i}=\left(x_{i}+\alpha_{i} t_{y}\right) \mathrm{d} p_{x i}-\beta_{i} t_{y}\left(\mathrm{~d} \pi_{e}+\mathrm{d} t_{y}\right)+\Delta e_{y i} \mathrm{~d} \pi_{e} .
$$

We make use of (A22) and (A25) to transform (A18) into

$$
\mathrm{d} p_{x i}=\frac{\delta_{i}\left(\mathrm{~d} \pi_{e}+\mathrm{d} t_{y}\right)}{\gamma_{i}}+\frac{D_{z}^{i} \Delta e_{y i} \mathrm{~d} \pi_{e}}{\gamma_{i}}
$$

where $\delta_{i}:=\alpha_{i}-\beta_{i} t_{y} D_{z}^{i}$ and $\gamma_{i}:=\alpha_{i} X_{e}^{i}-D_{p}^{i}-\left(x_{i}+\alpha_{i} t_{y}\right) D_{z}^{i}$.

We insert (A26) into (A24) to obtain, after some rearrangement of terms,

$$
\mathrm{d} \pi_{e} \sum_{j} \frac{\alpha_{j} D_{z}^{j} \Delta e_{y j}}{\gamma_{j}}+\left(\mathrm{d} \pi_{e}+\mathrm{d} t_{y}\right) \sum_{j}\left[\frac{\alpha_{j} \delta_{j}}{\gamma_{j}}-\beta_{j}\right]=0
$$

which in turn can be rewritten as

$$
\frac{\mathrm{d} \pi_{e}}{\mathrm{~d} t_{y}}=-\frac{1}{1+\frac{\sum_{j} \frac{\alpha_{j} D_{z}^{j}}{\gamma_{j}} \Delta e_{y j}}{\sum_{j} \frac{\alpha_{j} \delta_{j}-\beta_{j} \gamma_{j}}{\gamma_{j}}}} .
$$


Next, we differentiate the utility function (2) to get $\mathrm{d} u_{i}=U_{x}^{i} \mathrm{~d} x_{i}+U_{y}^{i} \mathrm{~d} y_{i}$ and use $\frac{U_{x}^{i}}{p_{x i}}=$ $\frac{U_{y}^{i}}{p_{y}}=\lambda_{i}$ to obtain

$$
\frac{\mathrm{d} u_{i}}{\lambda_{i}}=p_{x i} \mathrm{~d} x_{i}+\mathrm{d} y_{i}
$$

where $\lambda_{i}$ is the marginal utility of income (i.e. the Lagrange multiplier assigned to the consumer's budget constraint). From (A3), (A8) and (A10) we infer

$$
\mathrm{d} x_{i}=X_{e}^{i} \mathrm{~d} e_{x i}=\frac{p_{e}+\pi_{e}+t_{y}}{p_{x i}} \mathrm{~d} e_{x i} .
$$

From (A16) we obtain with the help of (A15)

$$
\mathrm{d} y_{i}=t_{y} \mathrm{~d} e_{y i}-\left(p_{e}+\pi_{e}\right) \mathrm{d} e_{x i}+\Delta e_{y i} \mathrm{~d} \pi_{e} .
$$

Inserting (A30) and (A31) in (A29) gives

$$
\frac{\mathrm{d} u_{i}}{\lambda_{i}}=\left(p_{e}+\pi_{e}+t_{y}\right) \mathrm{d} e_{x i}+t_{y} \mathrm{~d} e_{y i}-\left(p_{e}+\pi_{e}\right) \mathrm{d} e_{x i}+\Delta e_{y i} \mathrm{~d} \pi_{e}=t_{y}\left(\mathrm{~d} e_{x i}+\mathrm{d} e_{y i}\right)+\Delta e_{y i} \mathrm{~d} \pi_{e}
$$

or, equivalently,

$$
\frac{\mathrm{d} u_{i}}{\lambda_{i} \mathrm{~d} t_{y}}=t_{y} \frac{\mathrm{d} e_{x i}+\mathrm{d} e_{y i}}{\mathrm{~d} t_{y}}+\Delta e_{y i} \frac{\mathrm{d} \pi_{e}}{\mathrm{~d} t_{y}}
$$

From (A23) it follows that

$$
\frac{\mathrm{d} e_{x i}+\mathrm{d} e_{y i}}{\mathrm{~d} t_{y}}=\alpha_{i} \frac{\mathrm{d} p_{x i}}{\mathrm{~d} t_{y}}-\beta_{i}\left(\frac{\mathrm{d} \pi_{e}}{\mathrm{~d} t_{y}}+1\right) .
$$

(A26) yields

$$
\frac{\mathrm{d} p_{x i}}{\mathrm{~d} t_{y}}=\frac{\delta_{i}}{\gamma_{i}}\left(\frac{\mathrm{d} \pi_{e}}{\mathrm{~d} t_{y}}+1\right)+\frac{D_{z}^{i} \Delta e_{y i}}{\gamma_{i}} \frac{\mathrm{d} \pi_{e}}{\mathrm{~d} t_{y}}
$$

Making use of (A35) in (A34) yields

$$
\frac{\mathrm{d} e_{x i}+\mathrm{d} e_{y i}}{\mathrm{~d} t_{y}}=\left(\frac{\alpha_{i} \delta_{i}}{\gamma_{i}}-\beta_{i}\right)\left(\frac{\mathrm{d} \pi_{e}}{\mathrm{~d} t_{y}}+1\right)+\frac{\alpha_{i} D_{z}^{i} \Delta e_{y i}}{\gamma_{i}} \frac{\mathrm{d} \pi_{e}}{\mathrm{~d} t_{y}} .
$$

We take advantage of (A36) to turn (A33) into

$$
\frac{\mathrm{d} u_{i}}{\lambda_{i} \mathrm{~d} t_{y}}=t_{y}\left(\frac{\alpha_{i} \delta_{i}-\beta_{i} \gamma_{i}}{\gamma_{i}}\right)\left(\frac{\mathrm{d} \pi_{e}}{\mathrm{~d} t_{y}}+1\right)+\left(\frac{\alpha_{i} t_{y} D_{z}^{i}+\gamma_{i}}{\gamma_{i}}\right) \Delta e_{y i} \frac{\mathrm{d} \pi_{e}}{\mathrm{~d} t_{y}}
$$

\section{Lemma 1.}

$$
\eta_{x z}^{i}<\frac{p_{e}+\pi_{e}+t_{y}}{t_{y}} \cdot \frac{z_{i}}{p_{x i} x_{i}} \quad \Longrightarrow \quad \gamma_{i}>0 .
$$

Proof. Observe that

$$
\gamma_{i}:=\alpha_{i} X_{e}^{i}-D_{p}^{i}-\left(x_{i}+\alpha_{i} t_{y}\right) D_{z}^{i}=\alpha_{i} X_{e}^{i}-\frac{p_{x i} D_{p}^{i}}{x_{i}} \cdot \frac{x_{i}}{p_{x i}}-\left(x_{i}+\alpha_{i} t_{y}\right) \frac{z_{i} D_{z}^{i}}{x_{i}} \cdot \frac{x_{i}}{z_{i}}
$$


Making use of the definitions $\eta_{x p}^{i}:=\frac{p_{x i} D_{p}^{i}}{x_{i}}$ and $\eta_{x z}^{i}:=\frac{z_{i} D_{z}^{i}}{x_{i}}$ (A39) turns into

$$
\gamma_{i}=\frac{x_{i}}{p_{x i}}\left[\frac{\alpha_{i} p_{x i}}{x_{i}} X_{e}^{i}-\eta_{x p}^{i}-\left(\frac{p_{x i} x_{i}}{z_{i}}+\frac{\alpha t_{y} p_{x i}}{z_{i}}\right) \eta_{x z}^{i}\right] .
$$

With the help of the Slutzky equation (in elasticity notation), formally $\eta_{x p}^{i}=\eta_{x p}^{c i}-\frac{p_{x i} x_{i}}{z_{i}} \eta_{x z}^{i}$ with $\eta_{x p}^{c i}:=\left.\frac{\partial x_{i}}{\partial p_{x i}} \cdot \frac{p_{x i}}{x_{i}}\right|_{u=\text { const. }}<0,(\mathrm{~A} 40)$ can be rearranged to yield

$$
\gamma=\frac{x_{i}}{p_{x i}}\left[\alpha_{i} p_{x i}\left(\frac{X_{e}^{i}}{x_{i}}-\frac{t_{y}}{z_{i}} \eta_{x z}^{i}\right)-\eta_{x p}^{c i}\right]
$$

Finally, we consider (A7) to obtain

$$
\frac{X_{e}^{i}}{x_{i}}-\frac{t_{y}}{z_{i}} \eta_{x z}^{i}=\frac{p_{e}+\pi_{e}+t_{y}}{p_{x i} x_{i}}-\frac{t_{y}}{z_{i}} \eta_{x z}^{i}=\frac{t_{y}}{p_{x i} x_{i}}\left(\frac{p_{e}+\pi_{e}+t_{y}}{t_{y}}-\frac{p_{x i} x_{i}}{z_{i}} \eta_{x z}^{i}\right) .
$$

Lemma 2. The term $\alpha_{i} \delta_{i}-\beta_{i} \gamma_{i}$ is negative.

Proof. Observe that

$$
\begin{aligned}
\alpha_{i} \delta_{i}-\beta_{i} \gamma_{i} & =\alpha_{i}\left(\alpha_{i}-\beta_{i} t_{y} D_{z}^{i}\right)-\beta_{i}\left[\alpha_{i} X_{e}^{i}-D_{p}^{i}-\left(x_{i}+\alpha_{i} t_{y}\right) D_{z}^{i}\right] \\
& =\alpha_{i}\left(\alpha_{i}-\beta_{i} X_{e}^{i}\right)+\beta_{i}\left(D_{p}^{i}+x_{i} D_{z}^{i}\right)
\end{aligned}
$$

Making use of the definitions of $\beta_{i}$ and the elasticities $\eta_{x p}^{i}$ and $\eta_{x z}^{i}$, and making use of the Slutzky equation we obtain

$$
\alpha_{i} \delta_{i}-\beta_{i} \gamma_{i}=\alpha_{i} \frac{X_{e}^{i}}{Y_{e e}^{i}}+\beta_{i} \frac{x_{i}}{p_{x i}}\left(\eta_{x p}^{i}+\frac{p_{x i} x_{i}}{z_{i}} \eta_{x z}^{i}\right)=\alpha_{i} \frac{X_{e}^{i}}{Y_{e e}^{i}}+\beta_{i} \frac{x_{i}}{p_{x i}} \eta_{x p}^{c i} .
$$

\section{Comparative statics for quasi-linear utility functions (Table 3)}

While $\mathrm{d} \pi_{e}$ and $\mathrm{d} u_{i}$ follows from setting $D_{z}^{i}=0$ in (20) and (16), $\mathrm{d} p_{x i}, \mathrm{~d} e_{y i}, \mathrm{~d} e_{x i}, \mathrm{~d} x_{i}, \mathrm{~d} y_{i}$, $\mathrm{d} z_{i}$ follows from (A26), $\mathrm{d} e_{y i}=\frac{\mathrm{d} \pi_{e}+\mathrm{d} t_{y}}{Y_{e e}^{i}},(\mathrm{~A} 22),(\mathrm{A} 30),(\mathrm{A} 31)$ and (A25), respectively. 


\section{Appendix B: Comparative statics of the parametric model}

For the parametric functional forms $U^{i}\left(x_{i}, y_{i}\right)=x_{i}^{h_{i}} y_{i}^{1-h_{i}}, X^{i}\left(e_{x i}\right)=e_{x i}^{a_{i}}, Y^{i}\left(e_{y i}\right)=e_{y i}^{b_{i}}$ the cost-effective competitive equilibrium is determined by

$$
\begin{aligned}
\sum_{j} c_{j} & =\sum_{j}\left(e_{x j}+e_{y j}\right), \\
e_{x i}^{a_{i}} & =\frac{h_{i} z_{i}}{p_{x i}} \\
z_{i} & =p_{x i} e_{x i}^{a_{i}}+e_{y i}^{b_{i}}-\left(q_{e}-t_{y}\right)\left(e_{x i}+e_{y i}\right)+\pi_{e} c_{i}, \\
p_{x i} a_{i} e_{x i}^{a_{i}-1} & =b_{i} e_{y i}^{b_{i}-1}=q_{e}, \\
b_{i} e_{y i}^{b_{i}-1} & =q_{e} \\
y_{i} & =e_{y i}^{b_{i}}-\left(q_{e}-t_{y}\right)\left(e_{x i}+e_{y i}\right)+\pi_{e} c_{i},
\end{aligned}
$$

where $q_{e}:=p_{e}+\pi_{e}+t_{y}$. Note that (B2), (B3) and (B6) imply

$$
y_{i}=\left(1-h_{i}\right) z_{i}
$$

Next we rearrange the system of equations (B1)-(B5). We make use of (B2) and (B4) to get

$$
z_{i}=\frac{e_{x i} q_{e}}{a_{i} h_{i}}
$$

From (B4) and (B5) we obtain

$$
p_{x i} e_{x i}^{a_{i}}=\frac{e_{x i} q_{e}}{a_{i}}
$$

We rearrange (B5) and write

$$
e_{y i}^{b_{i}}=\frac{e_{y i} q_{e}}{b_{i}}
$$

We make use of (B8)-(B10) in (B3) to get

$$
\left[\frac{\left(1-h_{i}\right)+a_{i} h_{i}}{a_{i} h_{i}} q_{e}-t_{y}\right] e_{x i}-\left[\frac{1-b_{i}}{b_{i}} q_{e}+t_{y}\right] e_{y i}-\pi_{e} c_{i}=0 .
$$

Total differentiation of (B1), (B5), (B6) and (B11) yields

$$
\begin{gathered}
\sum_{j}\left(\mathrm{~d} e_{x j}+\mathrm{d} e_{y j}\right)=0 \\
\mathrm{~d} e_{y i}=-\frac{e_{y i}}{\left(1-b_{i}\right) q_{e}}\left(\mathrm{~d} \pi_{e}+d t_{y}\right) \\
\mathrm{d} z_{i}=\frac{\mathrm{d} y_{i}}{1-h_{i}}, \\
{\left[\frac{\left(1-h_{i}\right)+a_{i} h_{i}}{a_{i} h_{i}} q_{e}-t_{y}\right] \mathrm{d} e_{x i}-\left(\frac{1-b_{i}}{b_{i}} q_{e}+t_{y}\right) \mathrm{d} e_{y i}-\mathrm{d} \pi_{e} c_{i}} \\
+e_{x i}\left[\frac{1-h_{i}+a_{i} h_{i}}{a_{i} h_{i}} \mathrm{~d} \pi_{e}+\frac{1-h_{i}}{a_{i} h_{i}} \mathrm{~d} t_{y}\right]-e_{y i}\left[\frac{1-b_{i}}{b_{i}} \mathrm{~d} \pi_{e}+\frac{\mathrm{d} t_{y}}{b_{i}}\right]=0 .
\end{gathered}
$$


(B15) can be rearranged to read

$$
\frac{\mathrm{d} e_{x i}}{\rho_{i}}=\Delta e_{y i} \mathrm{~d} \pi_{e}-\left(\frac{1-b_{i}}{b_{i}} q_{e}+t_{y}\right) \mathrm{d} e_{y i}+\left(\mathrm{d} \pi_{e}+\mathrm{d} t_{y}\right)\left(\frac{\bar{h}_{i} e_{x i}}{a_{i}}-\frac{e_{y i}}{b_{i}}\right)
$$

where $\bar{h}_{i}:=\frac{1-h_{i}}{h_{i}}$ and $\rho_{i}:=\frac{a_{i}}{h_{i} q_{e}+a_{i}\left(p_{e}+\pi_{e}\right)}>0$. Inserting de $e_{y i}$ from (B13) in (B16) yields after some rearrangement of terms

$$
\frac{\mathrm{d} e_{x i}}{\rho_{i}}=\Delta e_{y i} \mathrm{~d} \pi_{e}-\left(\mathrm{d} \pi_{e}+\mathrm{d} t_{y}\right)\left[\frac{\bar{h}_{i} e_{x i}}{a_{i}}+\frac{t_{y} e_{y i}}{\left(1-b_{i}\right) q_{e}}\right] .
$$

In view of (B13) and (B17), the sum of $\mathrm{d} e_{x i}$ and $\mathrm{d} e_{y i}$ is equal to

$$
\mathrm{d} e_{x i}+\mathrm{d} e_{y i}=-\sigma_{i} \rho_{i}\left(\mathrm{~d} \pi_{e}+\mathrm{d} t_{y}\right)+\Delta e_{y i} \rho_{i} \mathrm{~d} \pi_{e}
$$

where $\sigma_{i}:=\frac{\bar{h}_{i} e_{x i}}{a_{i}}+\frac{\left(\bar{h}_{i}+a_{i}\right) e_{y i}}{\left(1-b_{i}\right) a_{i}}>0$. Next, we insert (B18) in (B12) to obtain

$$
\mathrm{d} \pi_{e} \sum_{j} \rho_{j}\left(\sigma_{j}-\Delta e_{y j}\right)=-\mathrm{d} t_{y} \sum_{j} \rho_{j} \sigma_{j} \Longleftrightarrow \frac{\mathrm{d} \pi_{e}}{\mathrm{~d} t_{y}}=-\frac{1}{1-\sum_{j} \frac{\rho_{j} \Delta e_{y j}}{\rho_{j} \sigma_{j}}}
$$

Totally differentiating (B4) yields

$$
\mathrm{d} p_{x i}=\frac{\left(1-a_{i}\right) p_{x i}}{e_{x i}} \mathrm{~d} e_{x i}+\frac{p_{x i}}{q_{e}}\left(\mathrm{~d} \pi_{e}+\mathrm{d} t_{y}\right)
$$

which with the help of (B17) can be turned into

$$
\mathrm{d} p_{x i}=\frac{\left(1-a_{i}\right) p_{x i} \rho_{i}}{e_{x i}} \Delta e_{y i} \mathrm{~d} \pi_{e}+\mu_{i}\left(\mathrm{~d} \pi_{e}+\mathrm{d} t_{y}\right)
$$

where $\mu_{i}:=\rho_{i} p_{x i}\left[\frac{\bar{h}_{i} q_{e}+a_{i}\left(p_{e}+\pi_{e}\right)}{a_{i} q_{e}}-\frac{\left(1-a_{i}\right)}{e_{x i}}\right] . \mathrm{d} x_{i}, \mathrm{~d} y_{i}, \mathrm{~d} z_{i}$ and $\mathrm{d} u_{i}$ have been calculated in (A30), (A31), (B14) and (A33). We make use of (B13), (B17) and (B18) to transform (A30), (A31), (B14) and (A33) into

$$
\begin{aligned}
\mathrm{d} x_{i} & =\frac{q_{e} \rho_{i}}{p_{x i}} \Delta e_{y i} \mathrm{~d} \pi_{e}-\left(\mathrm{d} \pi_{e}+\mathrm{d} t_{y}\right) \frac{q_{e} \rho_{i}}{p_{x i}}\left[\frac{\bar{h}_{i} e_{x i}}{a_{i}}+\frac{t_{y} e_{y i}}{\left(1-b_{i}\right) q_{e}}\right], \\
\mathrm{d} y_{i} & =-\left(p_{e}+\pi_{e}\right) \rho_{i} \Delta e_{y i} \mathrm{~d} \pi_{e}-\left(\mathrm{d} \pi_{e}+\mathrm{d} t_{y}\right) \rho_{i}\left[\frac{h_{i} e_{x i}}{a_{i}}+\frac{t_{y}}{\left(1-b_{i}\right) q_{e}}\left(e_{y i}+\frac{1}{\rho_{i}}\right)\right], \\
\mathrm{d} z_{i} & =-\frac{\left(p_{e}+\pi_{e}\right) \rho_{i} \Delta e_{y i}}{\left(1-h_{i}\right)} \mathrm{d} \pi_{e}-\frac{\left(\mathrm{d} \pi_{e}+\mathrm{d} t_{y}\right) \rho_{i}}{\left(1-h_{i}\right)}\left[\frac{h_{i} e_{x i}}{a_{i}}+\frac{t_{y}}{\left(1-b_{i}\right) q_{e}}\left(e_{y i}+\frac{1}{\rho_{i}}\right)\right] \\
\frac{\mathrm{d} u_{i}}{\lambda_{i}} & =-t_{y} \sigma_{i} \rho_{i}\left(\mathrm{~d} \pi_{e}+\mathrm{d} t_{y}\right)+\left(t_{y} \rho_{i}+1\right) \Delta e_{y i} \mathrm{~d} \pi_{e} .
\end{aligned}
$$

The signs in Table 4 follow from setting $\mathrm{d} \pi_{e}=-\mathrm{d} t_{y}$ in (B13), (B17), (B21)-(B25). 


\section{Appendix C: Numerical example}

In this Appendix $\mathrm{C}$ we show how we solved the equilibrium equation system in order to simulate the graphs. Recall that for the special functional forms the multi-country equilibrium is determined by (B1)-(B6). In the following, we transform the equations (B1)(B6). First, we eliminate the variables $p_{x i}$ and $z_{i}$ through substitution. Invoking $z_{i}=\frac{e_{x}^{a_{i}} p_{x i}}{\sigma_{i}}$ from (B2) in (B3) we get

$$
p_{x i} e_{x i}^{a_{i}} \frac{\left(1-\sigma_{i}\right)}{\sigma_{i}}=e_{y i}^{b_{i}}-\left(q_{e}-t_{y}\right)\left(e_{x i}+e_{y i}\right)+\pi_{e} c_{i}
$$

Next, we insert $p_{x i}=\frac{q_{e}}{a_{i} e_{x i}^{a_{i}-1}}$, which follows from (B4) and (B5), in (C1) to obtain

$$
\begin{aligned}
e_{x i}\left[q_{e} \frac{\left(1-\sigma_{i}\right)}{a_{i} \sigma_{i}}+\left(q_{e}-t_{y}\right)\right] & =e_{y i}^{b_{i}}-\left(q_{e}-t_{y}\right) e_{y i}+\pi_{e} c_{i} \\
\Longleftrightarrow e_{x i}+e_{y i} & =\frac{e_{y i}^{b_{i}}-\left(q_{e}-t_{y}\right) e_{y i}+\pi_{e} c_{i}}{q_{e} \frac{\left(1-\sigma_{i}\right)}{a_{i} \sigma_{i}}+\left(q_{e}-t_{y}\right)}+e_{y i} \\
& =\frac{e_{y i}^{b_{i}}+\frac{q_{e}\left(1-\sigma_{i}\right)}{a_{i} \sigma_{i}} e_{y i}+\pi_{e} \cdot c_{i}}{q_{e} \frac{\left(1-\sigma_{i}\right)}{a_{i} \sigma_{i}}+\left(q_{e}-t_{y}\right)} .
\end{aligned}
$$

The equations (B1), (B5) and (C2) now determine the equilibrium values of $e_{x i}, e_{y i}$ for all $i$ and $\pi_{e}$. Next, we insert $e_{y i}=\left(\frac{q_{e}}{b_{i}}\right)^{\frac{1}{b_{i}-1}}$ from (B5) in (C2) which yields

$$
e_{x i}+e_{y i}=\frac{\left(\frac{q_{e}}{b_{i}}\right)^{\frac{b_{i}}{b_{i}-1}}+\frac{q_{e}\left(1-\sigma_{i}\right)}{a_{i} \sigma_{i}}\left(\frac{q_{e}}{b_{i}}\right)^{\frac{1}{b_{i}-1}}+\pi_{e} c_{i}}{q_{e} \frac{\left(1-\sigma_{i}\right)}{a_{i} \sigma_{i}}+\left(q_{e}-t_{y}\right)},
$$

which in turn is inserted into (B1) to obtain

$$
\sum_{i} \frac{\left(\frac{q_{e}}{b_{i}}\right)^{\frac{b_{i}}{1-b_{i}}}+\frac{q_{e}\left(1-\sigma_{i}\right)}{a_{i} \sigma_{i}}\left(\frac{q_{e}}{b_{i}}\right)^{\frac{1}{1-b_{i}}}+\pi_{e} c_{i}}{q_{e} \frac{\left(1-\sigma_{i}\right)}{a_{i} \sigma_{i}}+\left(q_{e}-t_{y}\right)}=\sum_{i} c_{i} .
$$

Equation (C4) implicitly determines $\pi_{e}$ as a function of $t_{y}$, formally $\pi_{e}=\pi_{e}\left(t_{y}\right)$. Then we can compute $e_{y i}\left(t_{y}\right)$ from $(\mathrm{B} 5), e_{x i}\left(t_{y}\right)$ from $(\mathrm{B} 4), \Delta e_{y i}\left(t_{y}\right)$ from $(\mathrm{C} 3), x_{i}\left(t_{y}\right)$ from $x_{i}=X^{i}\left(e_{x i}\right), y_{i}\left(t_{y}\right)$ from (B6), $z_{i}\left(t_{y}\right)$ from $(\mathrm{B} 7)$ and $u_{i}\left(t_{y}\right)$ from $u_{i}=x_{i}^{h_{i}} y_{i}^{1-h_{i}}$.

The missing graphs of the numerical example are presented in the Figures 4-8. 


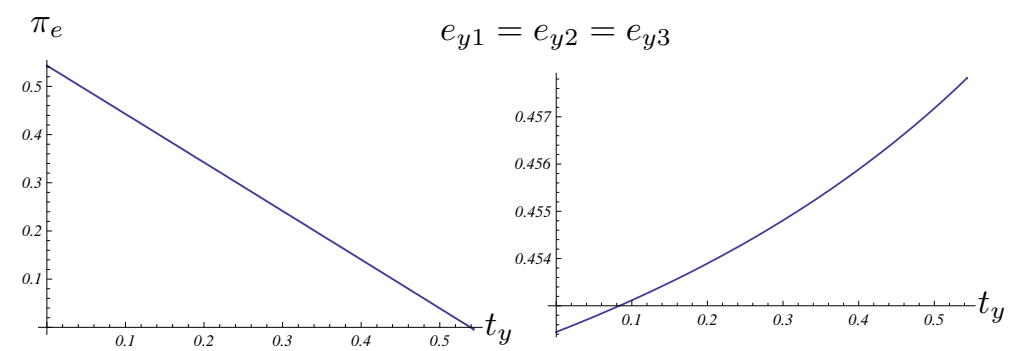

Figure 4: The permit price, the emissions in sector $Y$

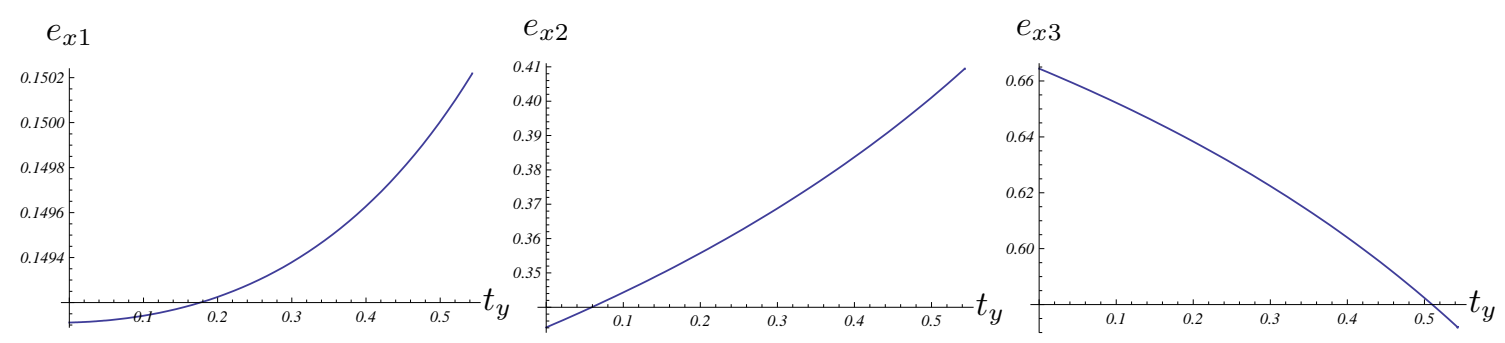

Figure 5: The emissions in sector $X$
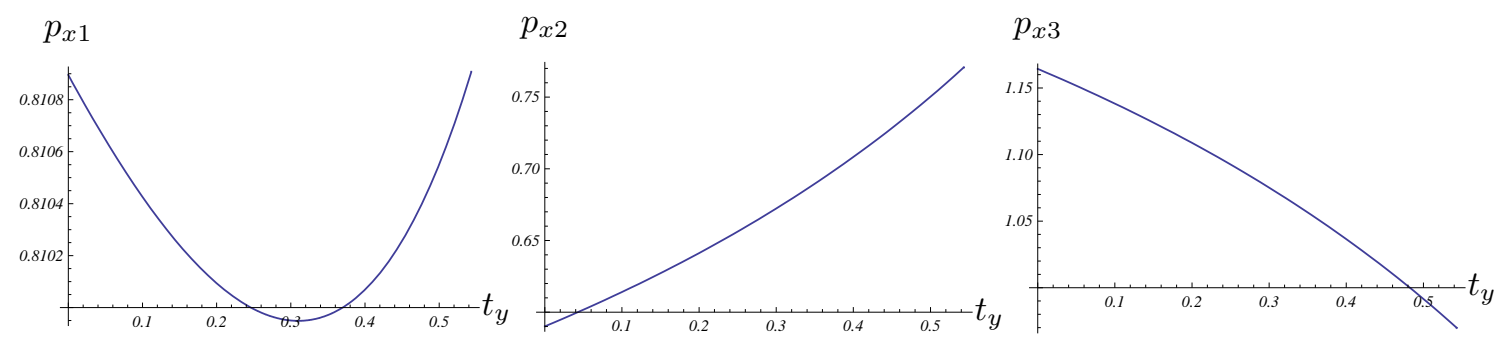

Figure 6: The domestic price of good $X$

\begin{tabular}{|c|c|c|c|c|c|c|}
\hline & \multicolumn{2}{|c|}{$i=1$} & \multicolumn{2}{|c|}{$i=2$} & \multicolumn{2}{|c|}{$i=3$} \\
\hline & $t_{y}=0$ & $\begin{array}{c}\pi_{e}=0 \\
\bar{t}_{y}\end{array}$ & $t_{y}=0$ & $\begin{array}{c}\pi_{e}=0 \\
\overline{t_{y}}\end{array}$ & $t_{y}=0$ & $\begin{array}{c}\pi_{e}=0 \\
\bar{t}_{y}\end{array}$ \\
\hline$p_{x i}$ & 0.811 & 0.811 & 0.590 & 0.771 & 0.149 & 0.970 \\
\hline$e_{x i}$ & 0.149 & 0.150 & 0.334 & 0.409 & 0.664 & 0.572 \\
\hline$e_{y i}$ & 0.452 & 0.458 & 0.452 & 0.458 & 0.452 & 0.458 \\
\hline$\Delta e_{y i}$ & 0.003 & -0.003 & -0.186 & -0.267 & 0.318 & 0.270 \\
\hline$x_{i}$ & 0.683 & 0.684 & 0.518 & 0.585 & 0.692 & 0.605 \\
\hline$y_{i}$ & 0.554 & 0.555 & 0.414 & 0.504 & 0.549 & 0.470 \\
\hline$z_{i}$ & 1.108 & 1.110 & 0.828 & 1.009 & 1.097 & 0.939 \\
\hline$u_{i}$ & 0.615 & 0.533 & 1.097 & 0.543 & 0.616 & 0.811 \\
\hline
\end{tabular}

Table 6: Numerical values for $t_{y}=0, \pi_{e}=0$ 

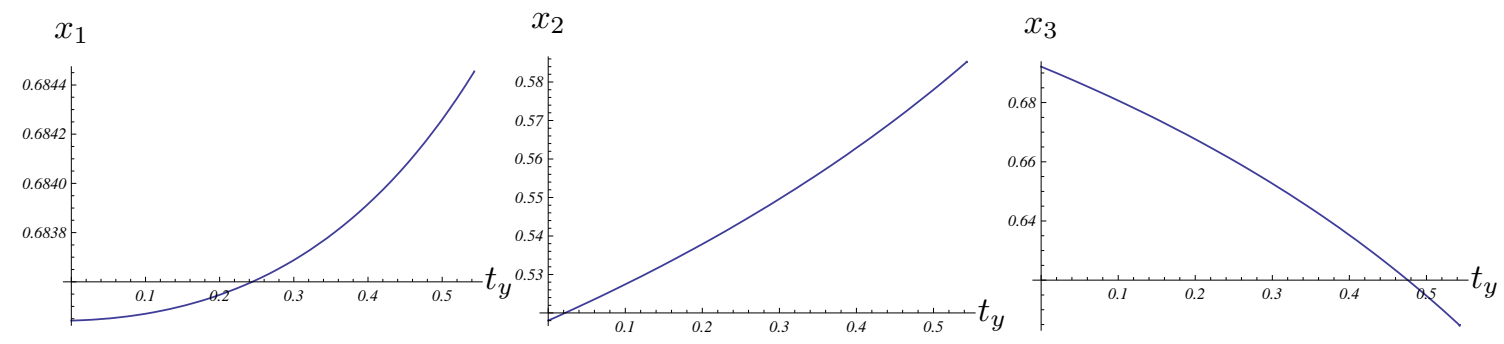

Figure 7: The consumption of good $X$

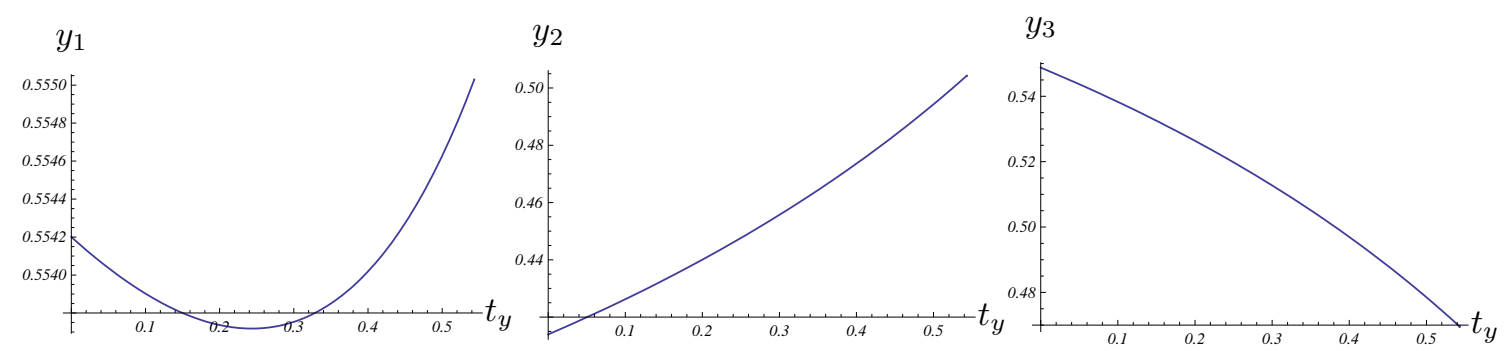

Figure 8: The consumption of good $Y$

\section{Appendix D: Proof of Proposition 6}

The cost-effective competitive equilibrium of the two-sector economy with domestic ETS is described by $c_{i}=e_{x i}+e_{y i}$ and (A2) - (A10). This equation system can be compressed to $c_{i}=e_{x i}+e_{y i}$ and (A12) - (A16). Total differentiation yields

$$
\begin{array}{r}
\mathrm{d} e_{x i}=-\mathrm{d} e_{y i}, \\
X_{e}^{i} \mathrm{~d} e_{x i}-D_{p}^{i} \mathrm{~d} p_{x i}-D_{z}^{i} \mathrm{~d} z_{i}=0, \\
\mathrm{~d} z_{i}=x_{i} \mathrm{~d} p_{x i}, \\
X_{e}^{i} \mathrm{~d} p_{x i}+p_{x i} X_{e e}^{i} \mathrm{~d} e_{x i}-Y_{e e}^{i} \mathrm{~d} e_{y i}=0, \\
Y_{e e}^{i} \mathrm{~d} e_{y i}-\mathrm{d} \pi_{e}-\mathrm{d} t_{y}=0 .
\end{array}
$$

Making use of (D1) in (D4) yields

$$
\mathrm{d} e_{x i}=-\frac{X_{e}^{i}}{p_{x i} X_{e e}^{i}+Y_{e e}^{i}} \mathrm{~d} p_{x i} .
$$

Making use of (D3) in (D2) we obtain

$$
\mathrm{d} e_{x i}=\frac{D_{p}^{i}+x_{i} D_{z}^{i}}{X_{e}^{i}} \mathrm{~d} p_{x i}
$$

Since in general $-\frac{X_{e}^{i}}{p_{x i} X_{e e}^{i}+Y_{e e}^{i}} \neq \frac{D_{p}^{i}+x_{i} D_{z}^{i}}{X_{e}^{i}},(\mathrm{D} 6)$ and (D7) are satisfied if and only if $\mathrm{d} e_{x i}=$ $\mathrm{d} p_{x i}=0$. With that observation we infer $\mathrm{d} e_{y i}=\mathrm{d} z_{i}=0$ and $\mathrm{d} \pi_{e}=-\mathrm{d} t_{y}$. 


\section{Appendix E: Comparative statics of one-sector economies}

For given prices $p_{e}$ and $p_{y}$ and for given emissions tax rate $t_{y}$ the cost-effective competitive equilibrium is determined by

$$
\begin{aligned}
\sum_{j} c_{y j} & =\sum_{j} e_{y j}, & & \\
z_{i} & =p_{y} y_{s i}+\pi_{e} \Delta e_{i}-p_{e} e_{y i}, & & i=1, \ldots, n, \\
y_{s i} & =Y^{i}\left(e_{y i}\right), & & i=1, \ldots, n, \\
z_{i} & =p_{y} y_{i}, & & i=1, \ldots, n, \\
Y_{e}^{i} & =p_{e}+\pi_{e}+t_{y}, & & i=1, \ldots, n,
\end{aligned}
$$

where $\Delta e_{y i}:=c_{y i}-e_{y i}$ is the amount of permits exported or imported by country $i$. In the following we carry out a comparative static analysis to specify the impact of exogenous variations in the uniform tax rate $t_{y}$. Without loss of generality we set $p_{y} \equiv 1$. Total differentiation of (E1) - (E5) yields

$$
\begin{aligned}
0 & =\sum_{j} \mathrm{~d} e_{y j} \\
\mathrm{~d} z_{i} & =\mathrm{d} y_{s i}+\mathrm{d} \pi_{e} \Delta e_{i}-\left(p_{e}+\pi_{e}\right) \mathrm{d} e_{y i} \\
\mathrm{~d} y_{s i} & =Y_{e}^{i} \mathrm{~d} e_{y i} \\
\mathrm{~d} z_{i} & =\mathrm{d} y_{i} \\
Y_{e e}^{i} \mathrm{~d} e_{y i} & =\mathrm{d} \pi_{e}+\mathrm{d} t_{y} .
\end{aligned}
$$

Inserting (E10) into (E6) we obtain

$$
\left(\mathrm{d} \pi_{e}+d t_{y}\right) \sum_{j} \frac{1}{Y_{e e}^{i}}=0 \Longleftrightarrow \frac{\mathrm{d} \pi_{e}}{\mathrm{~d} t_{y}}=-1 .
$$

We make use of (E11) in (E10) to get

$$
\frac{\mathrm{d} e_{y i}}{\mathrm{~d} t_{y}}=0
$$

and from (E8) we infer

$$
\frac{\mathrm{d} y_{s i}}{\mathrm{~d} t_{y}}=0
$$

Next, we take advantage of (E11), (E12) and (E13) to rewrite (E7) as

$$
\frac{\mathrm{d} z_{i}}{\mathrm{~d} t_{y}}=-\Delta e_{y i}
$$


Finally, we insert (E14) into (E9) to get

$$
\frac{\mathrm{d} y_{i}}{\mathrm{~d} t_{y}}=-\Delta e_{y i}
$$

which in turn is inserted into $\mathrm{d} u_{i}=U_{y}^{i} \mathrm{~d} y_{i}$ to establish

$$
\frac{\mathrm{d} u_{i}}{\mathrm{~d} t_{y}}=-U_{y}^{i} \Delta e_{y i}
$$

